\title{
Oxide and Organic-Inorganic Halide Perovskites with Plasmonics for Optoelectronic and Energy Applications: A Contributive Review
}

\author{
Brahim Aïssa *, Adnan Ali (D) and Fedwa El-Mellouhi (D) \\ Qatar Environment and Energy Research Institute (QEERI), Hamad Bin Khalifa University (HBKU), \\ Doha P.O. Box 34110, Qatar; adali@hbku.edu.qa (A.A.); felmellouhi@hbku.edu.qa (F.E.-M.) \\ * Correspondence: baissa@hbku.edu.qa or brahim.aissa@mpbc.ca; Tel.: +947-4454-7475
}

Citation: Aïssa, B.; Ali, A.;

El-Mellouhi, F. Oxide and

Organic-Inorganic Halide

Perovskites with Plasmonics for

Optoelectronic and Energy

Applications: A Contributive Review.

Catalysts 2021, 11, 1057. https://

doi.org/10.3390/catal11091057

Received: 11 August 2021

Accepted: 29 August 2021

Published: 31 August 2021

Publisher's Note: MDPI stays neutral with regard to jurisdictional claims in published maps and institutional affiliations.

Copyright: (c) 2021 by the authors. Licensee MDPI, Basel, Switzerland. This article is an open access article distributed under the terms and conditions of the Creative Commons Attribution (CC BY) license (https:// creativecommons.org/licenses/by/ $4.0 /)$.

\begin{abstract}
The ascension of halide perovskites as outstanding materials for a wide variety of optoelectronic applications has been reported in recent years. They have shown significant potential for the next generation of photovoltaics in particular, with a power conversion efficiency of $25.6 \%$ already achieved. On the other hand, oxide perovskites have a longer history and are considered as key elements in many technological applications; they have been examined in depth and applied in various fields, owing to their exceptional variability in terms of compositions and structures, leading to a large set of unique physical and chemical properties. As of today, a sound correlation between these two important material families is still missing, and this contributive review aims to fill this gap. We report a detailed analysis of the main functions and properties of oxide and organic-inorganic halide perovskite, emphasizing existing relationships amongst the specific performance and the structures.
\end{abstract}

Keywords: oxide perovskite; metal-halide perovskite; plasmonics; photovoltaics; optoelectronics

\section{Introduction}

Materials crystalizing in the perovskite crystal structure are common crystals that are currently employed for multiples applications, including transistors [1], solar cells, light-emitting devices [2], memories [3], catalysts [4], and superconductors [5].

One of the biggest players within the perovskite structures is the family of oxide perovskites. This is a prominent family with the general formula of $\mathrm{ABO}_{3}$, where $\mathrm{A}$ commonly designates an alkaline or rare earth metal cation, occupying the 12-fold coordinated cuboctahedral cages of the oxygen sub-lattice, and B stands for a transition-metal cation (e.g., Fe, $\mathrm{Ni}, \mathrm{Mn}, \mathrm{Co}, \mathrm{Cu}$, or Ti) coordinated with six oxygen atoms in an octahedral coordination [6].

In fact, in the perovskite structure, distortions frequently occur due to the deviation from ideal values of ionic size ratios between the different $A, B$, and $O$ sites of the crystal. In addition, $\mathrm{A}$ or $\mathrm{B}$ cations may have distinctive sizes and valences that could result into oxygen non-stoichiometry, involving both oxygen excess and/or oxygen deficiency.

Perovskite oxides also have high versatility in redox active sites, physico-chemical properties, and oxygen vacancies with controllable compositions, due to several potential substitutions at both $\mathrm{A}$ and $\mathrm{B}$ sites. For instance, they might be organized either as double perovskite structure of $\mathrm{A}_{2} \mathrm{BB}^{\prime} \mathrm{O}_{6}[7,8]$ or as layered perovskite, depending on their composition or crystal structure. In addition to the composition and the structure, physical and chemical properties are also governed by the perovskite oxides morphology [6,9].

From a historical point of view, the most abundant minerals in the mantle and the crust of our planet are oxides. They constitute minerals with various degrees of structural complexity, ranging from the simplest rock-salt structure to the complex silicates. One of the most dominant families among these minerals is the perovskite structure, which forms a rather simple arrangement but offers an extremely rich variety of cations.

The name "perovskite" was given in honor of the Russian nobleman the Count Lev Alexander Von Perovski (1792-1856), who was a passionate geologist under the Tsar Nicolas 
1st era. In 1829, Gustav Rose discovered the first $\mathrm{CaTiO}_{3}$ perovskite in the Ural Mountains (western Russia). Furthermore, a countless amount of research has been conducted; both $\mathrm{ABO}_{3}$ oxide perovskites and $\mathrm{A}_{2} \mathrm{BB}^{\prime} \mathrm{O}_{6}$ double perovskites were investigated for more than a century, much before the emanation of halide perovskites.

To cite few typical applications, manganese-based oxide perovskites were dominating for their magnetoresistance property, whereas "cuprates" containing anionic copper complexes have been systematically employed for decades as high-temperature superconducting prototypical systems [10]. Electromagnetic absorption has been efficiently demonstrated using $\mathrm{Bi}_{2} \mathrm{FeCrO}_{6}$, and more recently, many studies have been initiated to explore the bulk photovoltaic properties of these oxides; perovskite and the double $\mathrm{Bi}_{2} \mathrm{FeCrO}_{6}$ perovskite have demonstrated a power-conversion efficiency up to $8.1 \%$ [11-13]. Furthermore, calculations and modeling studies have showed that alloys of $\mathrm{Ba}_{2} \mathrm{SbV}_{0.25} \mathrm{Ta}_{0.75} \mathrm{O}_{6}$ oxide double perovskites have a huge potential for solar cell applications [13].

The second pillar of the perovskite family is halide. It has attracted unprecedented interest, from technological as well as scientific perspectives, and even revolutionized the field of emerging photovoltaics within a short period of time [14,15]. In fact, lead-halide PSCs have hit world-record efficiencies above $25.6 \%$, exceeding state-of-the-art thin-film silicon and CIGS technologies [16-18].

Oxides account for roughly $70 \%$ of the identified compounds of current perovskites, whereas halides account for just 16\% [19]. Surprisingly, there is no particular duplication between these two subclasses, and there is also no direct link between these two areas.

This paper summarizes and reviews inorganic perovskites as well as well as future expectations. Using nanoparticles that utilize plasmonics effects also highlights the viability of using photon and charge carriers.

Figure 1a displays the recent references related to the oxide perovskite in terms of the distribution of the publications per discipline and applications. Observing Figure $1 b$, one might notice that the dominating disciplines are physics, material science, chemistry and engineering, with less emergence in other closely related fields such as environmental sciences. This is further evident from Figure 1c, which shows the distribution in terms of application domains; the dominance in the areas of fuel cells, photocatalysis and solar cells is clear.

(a)

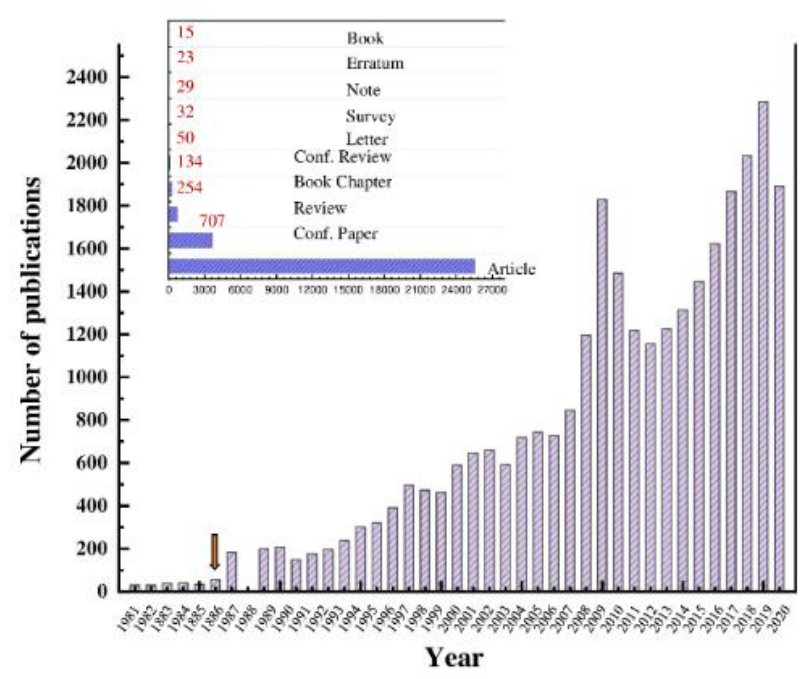

(b)

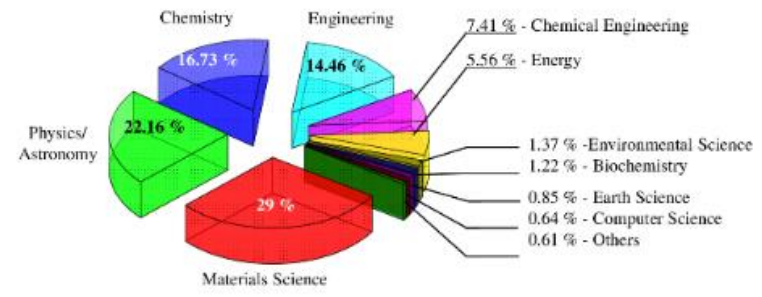

(c)

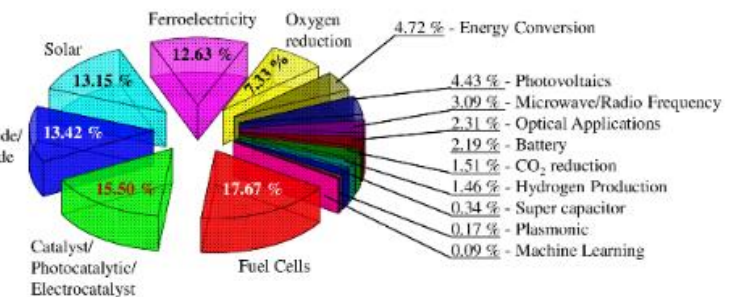

Figure 1. (a) Latest studies on the oxide perovskite field and their respective distribution of the key words employed and histogram of the type of documents, in the inset. (b) Distribution of the publications per discipline and per (c) applications. 


\section{Structure of Oxide Perovskite}

In the ideal cubic unit cell of a perovskite compound, type " $\mathrm{A}$ " atoms are located at the cube corner, at the positions $(0,0,0)$, type " $B$ " atoms at the center position $(1 / 2,1 / 2$, $1 / 2)$ and oxygen atoms located at the face positions $(1 / 2,1 / 2,0)$. Figure $2 a$ shows a ball and stick representation of cubic unit cell where A ions occupy the edges, B ions the center and $\mathrm{O}$ ions occupy the faces.

(a)

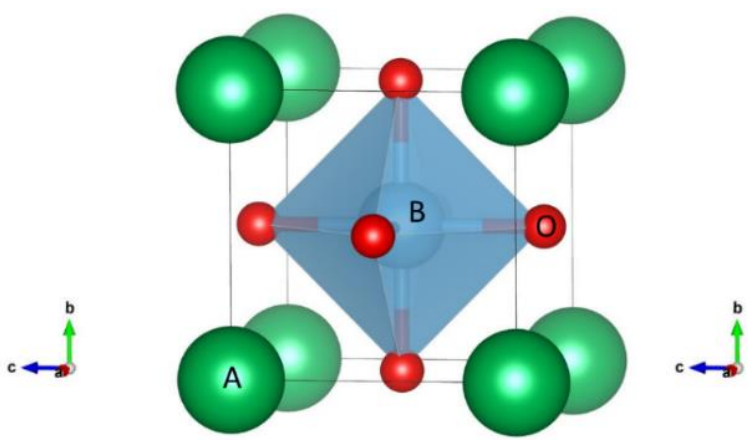

(b)

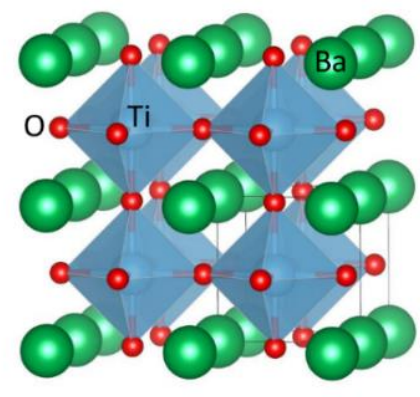

Figure 2. Stick and ball and stick schematic of the (a) ideal cubic perovskite structure unit cell, and (b) a supercell for $\mathrm{BaTiO}_{3}$ structure.

The relative ion size rules that govern the stability of the ideal cubic structure such as the "Goldsmith tolerance factor" are quite rigid, such that minor buckling and octahedral distortion shall reduce the distorted versions of the symmetry in which the coordination numbers of $\mathrm{A}, \mathrm{B}$ or both cations are reduced. $\mathrm{BO}_{6}$ octahedral tilting decreases the coordination of an undersized A cation from 12 to as low as 8 . In fact, it helps in attaining a stable bond pattern by removing a small $\mathrm{B}$ cation from the center of this octahedron. The resulting electric dipole is the key factor governing the ferroelectricity as shown by perovskites, for example $\mathrm{BaTiO}_{3}$ (Figure 2b) that distort in this fashion. The most predominant non-cubic variants are the orthorhombic and tetragonal phases. Double perovskites can form upon the incorporation of two distinct B-site cations, forming complex perovskite structures and leading to the formation of ordered and disordered crystal structures.

Complex or mixed oxides are cation groups that contain two or more distinct cations. There are several types of crystal structures. In certain distinctive cases, oxides of a single cation are often known as mixed oxides in different oxidation states.

Perovskite is another significant mixed oxide structure, and many similar oxide structures are known perovskites. The structure of the ilmenite is the same as that of perovskite, i.e., $\mathrm{ABO}_{3}$, where in this structure, $\mathrm{A}$ and $\mathrm{B}$ are cations occupying octahedral site of somewhere around the same size; however, the anion packing arrangement is hexagonal and compact in the ilmenite, whereas in the perovskite, the anion and A cation form a close, compact, and a cubic packing structure. Ilmenite has similar stoichiometry to perovskite, but the chemical formula is different. The key difference between ilmenite and perovskite is that ilmenite is an iron-based titanium oxide, i.e., $\mathrm{FeTiO}_{3}$ mineral, whereas perovskite is a calcium-based titanium oxide, i.e., $\mathrm{CaTiO}_{3}$ mineral. Moreover, another significant difference between ilmenite and perovskite is that ilmenite is weakly magnetic, whereas perovskite is a non-magnetic material.

In oxide compounds, perovskite oxides have vast families and many perovskiterelated structures have been already identified. Large-sized 12-coordinated A-site cations and smaller 6-coordinated B-site cations are standard structures. Wide ranges of oxides and halides, as well as sulfides and perovskites, have a perovskite composition. Because of Therefore, magnesium and iron silicates such as $(\mathrm{Mg}, \mathrm{Fe}) \mathrm{SiO}-$ or $\mathrm{CaSiO}_{3}$ are generally assumed as the geosphere's primary constituent. Scientists have discovered combinations of different charged cations in sites $A$ and $B$, such as $1+5,2+4$ and $3+3$, relating to 
various types of perovskite compounds. Although more complex combinations such as $\mathrm{Pb}\left(\mathrm{B}^{\prime} 1 / 2 \mathrm{~B}^{\prime \prime} 1 / 2\right)$ have been found. It is important to keep in mind that $\mathrm{B}^{\prime}$ is always a group containing $\mathrm{Sc}$ or $\mathrm{Fe}$, and $\mathrm{B}^{\prime \prime}$ is always a group containing $\mathrm{Nb}$ or Ta. Numerous $\mathrm{ABO}_{3}$ compounds often crystallize in polymorphic structures that exhibit a slight distortion from the perovskite structure symmetry.

For perovskite, a cubic lattice is the ideal structure and is shown in Figure 2. Numerous oxides have twisted a little with lower symmetries, despite the fact that few compounds have this ideal cubic structure (e.g., hexagonal or orthorhombic). In addition, although the ideal cubic structure of certain compounds may be intact, most oxides feature variants with a lower degree of symmetry. Table 1 lists many examples of perovskite oxides, where the perovskite oxides have mostly grown as rhombohedral lattices.

Table 1. Typical example of perovskite oxides, where the perovskite oxides have mostly grown as rhombohedral lattices.

\begin{tabular}{|c|c|c|c|}
\hline \multirow{2}{*}{ Compound } & \multicolumn{3}{|c|}{ Lattice Parameters (Å) } \\
\hline & a & $\mathbf{b}$ & c \\
\hline \multicolumn{4}{|l|}{ A. Cubic Structure } \\
\hline $\mathrm{KTaO}_{3}$ & 3.989 & & \\
\hline $\mathrm{NaTaO}_{3}$ & 3:929 & & \\
\hline $\mathrm{NaNbO}_{3}$ & 3:949 & & \\
\hline $\mathrm{BaMnO}_{3}$ & $4: 040$ & & \\
\hline $\mathrm{BaZrO}_{3}$ & $4: 193$ & & \\
\hline $\mathrm{SrTiO}_{3}$ & 3:904 & & \\
\hline $\mathrm{KMnF}_{3}$ & $4: 189$ & & \\
\hline $\mathrm{KFeF}_{3}$ & $4: 121$ & & \\
\hline \multicolumn{4}{|l|}{ B. Tetragonal Structure } \\
\hline $\mathrm{BiAlO}_{3}$ & $7: 61$ & & $7: 94$ \\
\hline $\mathrm{PbSnO}_{3}$ & $7: 86$ & & $8: 13$ \\
\hline $\mathrm{BaTiO}_{3}$ & 3:994 & & $4: 038$ \\
\hline $\mathrm{PdTiO}_{3}$ & $3: 899$ & & $4: 153$ \\
\hline $\mathrm{TlMnCl}_{3}$ & 5:02 & & $5: 04$ \\
\hline \multicolumn{4}{|l|}{ C. $\mathrm{LaAlO}_{3}$ type } \\
\hline $\mathrm{LaAlO}_{3}$ & $5: 357$ & $\alpha=60^{\circ} 06^{\prime}$ & \\
\hline $\mathrm{LaNiO}_{3}$ & $5: 461$ & $\alpha=60^{\circ} 05^{\prime}$ & \\
\hline $\mathrm{BiFeO}_{3}$ & $5: 632$ & $\alpha=60^{\circ} 06^{\prime}$ & \\
\hline $\mathrm{KNbO}_{3}$ & 4:016 & $\alpha=60^{\circ} 06^{\prime}$ & \\
\hline \multicolumn{4}{|l|}{ D. $\mathrm{GdFeO}_{3}$ type } \\
\hline $\mathrm{GdFeO}_{3}$ & $5: 346$ & $5: 616$ & $7: 668$ \\
\hline $\mathrm{YFeO}_{3}$ & $5: 283$ & $5: 592$ & $7: 603$ \\
\hline $\mathrm{NdGaO}_{3}$ & $5: 426$ & $5: 502$ & $7: 706$ \\
\hline $\mathrm{CaTiO}_{3}$ & $5: 381$ & $5: 443$ & $7: 645$ \\
\hline
\end{tabular}

A significant characteristic of many compounds is that they often have a wide degree of oxygen or cation deficiencies. The perovskite oxides share the large lattice energy, but due to the large cation and/or oxygen deficiencies, a substantial number of these compounds are nonetheless labeled as perovskite oxides. Ferromagnetism and ferroelectricity are associated forms of distortions within the perovskite structure. 
These $\mathrm{ABO}_{3}$ oxides are strictly termed as ionic crystals for a better understanding of the deviations from the ideal cubic structure. The radii of the $\mathrm{A}, \mathrm{B}$, and $\mathrm{O}_{2}-$ ions in the ideal structure have the following relationship:

$$
r_{A}+r_{O}=\sqrt{2\left(r_{B}+r_{O}\right)}
$$

Consequently, by using the Goldsmith tolerance factor $t$, ideal cubic structure deviancy can be determined in perovskite oxides:

$$
t=\frac{r_{A}+r_{O}}{\sqrt{2\left(r_{B}+r_{O}\right)}}
$$

The $t$ value in perovskite-type compounds is usually between 0.80 and 1.10 , i.e., an ideal cubic structure. $t$ values reflect the different polymorphs that exist for perovskite structures. In Figure 3, elements are shown which can be inserted into the perovskite structure are shown. Almost all elements, including dopants, will inhabit the perovskite structure at either A or B positions in the lattice, with the exception of noble gases. In terms of stability and crystal structure, for the A and B cations, ionic radii ratio of is the most significant factor for determining the perovskite structure stability. Structure is not only reliant on the size of the $\mathrm{A}$ and $\mathrm{B}$ atoms, but also on their chemical composition. For instance, $\mathrm{AMnO}_{3}$ forms a perovskite structure when the A cation is La or Ce-Dy, and forms a hexagonal structure when $\mathrm{A}=\mathrm{Ho}-\mathrm{Lu}$ or $\mathrm{Y}$ if $\mathrm{A}=\mathrm{La}$ or $\mathrm{Ce}-\mathrm{Dy}$ with 5- and 7coordination of $\mathrm{Mn}$ and A, respectively [17].
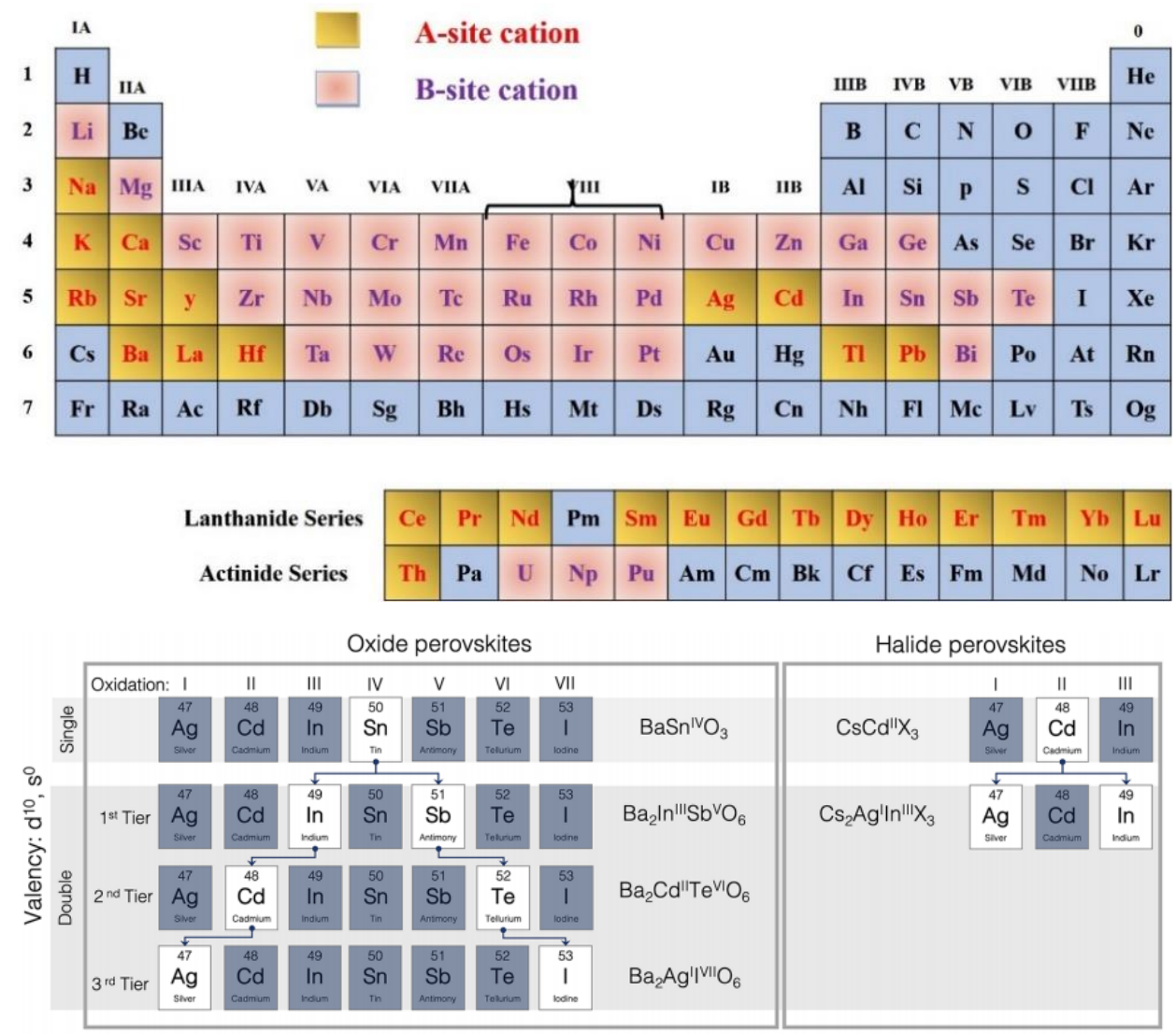

Figure 3. (Upper panel) In the perovskite structure, the B-site cation can be taken by chemical elements. (Lower panel) Representation of the oxide family (left), halides (right), single (top), and double (below) perovskites, and other analogs. 
At this site, the primary emphasis should be on the B atom's nature, where the covalent bond nature causes a coordination number of 6, which is rather low. The structure of $\mathrm{BaGeO}_{3}$ is an example of this kind. Although the ideal ionic size combination of $\mathrm{BaGeO}_{3}$ results in a $t$ value near to 1 , which implies the perovskite structure, $\mathrm{BaGeO}_{3}$ instead crystallizes in the silicate-related structure. The coordination number of $\mathrm{Ge}$ is four, which can be attributed to this. On the other hand, new Ge-based perovskite oxides have been identified from the developments in high-pressure technology [18]. By increasing the pressure, the Ge coordination number increases, and this higher coordination number is favorable for the formation of the perovskite structure, e.g., $\mathrm{CaGeO}_{3}$. Oxynitrides are another perovskite compounds group, i.e., $\mathrm{LaWO}_{3-\mathrm{x}} \mathrm{N}_{\mathrm{x}}, \mathrm{LaTaO}_{2} \mathrm{~N}$, etc. As a result, the ionic size which is dependent on the tolerance factor value $t$, is an important index for perovskite structure stability. However, the coordinating number contribution of the constituent elements must also be considered.

Next, superstructure formations in perovskites are discussed. Progressive substitution of the B-site cation by a dopant contributes to a significant difference in the ionic radii, and this can be conducive to the formation of the superstructures. $\mathrm{Ba}_{2} \mathrm{CaWO}_{6}$, also known as $\mathrm{Ba}_{2}(\mathrm{CaW}) \mathrm{O}_{6}$, is a clear example of this. Analogously, when $\mathrm{M}$ is $\mathrm{Fe}, \mathrm{Co}, \mathrm{Ni}, \mathrm{Zn}$, or $\mathrm{Ca}$, there is a random distribution of $\mathrm{M}$ and $\mathrm{Ta}$ ions in the octahedral positions in the compounds with the general formula $\mathrm{Ba}_{3} \mathrm{MTa}_{2} \mathrm{O}_{9}$, whereas $\mathrm{Ba}_{3} \mathrm{SrTa}_{2} \mathrm{O}_{9}$ forms a hexagonal lattice superstructure. On A sites, the cation vacancy ordering, as seen in $\mathrm{MNb}_{3} \mathrm{O}_{9}(\mathrm{M}=\mathrm{La}$, $\mathrm{Ce}, \mathrm{Pr}, \mathrm{Nb})$ and $\mathrm{MTa}_{3} \mathrm{O}_{9}(\mathrm{M}=\mathrm{La}, \mathrm{Ce}, \mathrm{Pr}, \mathrm{Nd}, \mathrm{Sm}, \mathrm{Gd}, \mathrm{Dy}, \mathrm{Ho}, \mathrm{Y}, \mathrm{Er})$, is another interesting form of superstructure observed in perovskites. Often known as the Brownmillalite $\left(\mathrm{A}_{2} \mathrm{~B}_{2} \mathrm{O}_{5}\right)$ and $\mathrm{K}_{2} \mathrm{NiF}_{4}$ structures, the perovskite polymorphs contain these two. The lowoxygen-deficiency type of perovskite, where oxygen vacancies are ordered, is known as Brownmillalite $\left(\mathrm{A}_{2} \mathrm{~B}_{2} \mathrm{O}_{5}\right)$.

In an ordered arrangement, the unit cell comprises $\mathrm{BO}_{6}$ and $\mathrm{BO}_{4}$. The A-site cation coordination number is reduced to eight due to the oxygen deficiency. For an ideal perovskite, the cubic lattice parameter $\left(a_{p}\right)$ is associated with the lattice parameter of Brownmillalite structure:

$$
\mathrm{a}=\mathrm{b}=\sqrt{2 a_{p} \mathrm{c}}=4 a_{p}
$$

Due to the large number of oxygen defects, Cu-based oxides and Ni-based oxides both develop oxygen-deficient structures. For exhibiting superconducting properties, $\mathrm{K}_{2} \mathrm{NiF}_{4}$ structures are well known and are found to be combined with ordered B-sites and oxygen defects.

Two units, namely the $\mathrm{KNiF}_{3}$ perovskite unit and the $\mathrm{KF}$ rock salt unit, are linked in series along the $c$ axis to form $\mathrm{K}_{2} \mathrm{NiF}_{4}$ structures. $\mathrm{K}_{2} \mathrm{NiF}_{4}$ is entrenched in the c-axis direction, and it has strong two-dimensional properties. There are several structures known as Ruddelsden-Popper compounds with the general formula $\left(\mathrm{ABO}_{3}\right) \mathrm{nAO}$ (see Figure 4), such as $\mathrm{Sr}_{3} \mathrm{Ti}_{2} \mathrm{O}_{7}(\mathrm{n}=2)$ and $\mathrm{Sr}_{4} \mathrm{Ti}_{3} \mathrm{O}_{10}(\mathrm{n}=3)$, based on the intergrowth of different numbers of $\mathrm{KNiF}_{3}$ and $\mathrm{KF}$ units [19]. The isostructural $\mathrm{Sr}_{2} \mathrm{TiO}_{4}$ or $\mathrm{Ca}_{2} \mathrm{MnO}_{4}$ can be contrasted with $\mathrm{SrTiO}_{3}$ or $\mathrm{CaMnO}_{3}$, which crystallize in perovskite structures. It is also possible to shape the perovskite and rock salt units with two separate A cations: an example of this is $\mathrm{LaO}_{\mathrm{nSrFeO}}$. An even more significantly modified version of $\mathrm{K}_{2} \mathrm{NiF}_{4}$ is where the two separate anions exclusively occupy the two building blocks, i.e., $\mathrm{SrFeO}_{3} . \mathrm{SrF}$ or $\mathrm{KNbO}_{3}$.KF. For any scenario, it is obvious that these structures are complex compounds. As a result, these compounds are supposed to possess various crystal properties and characteristics [20-22]. 


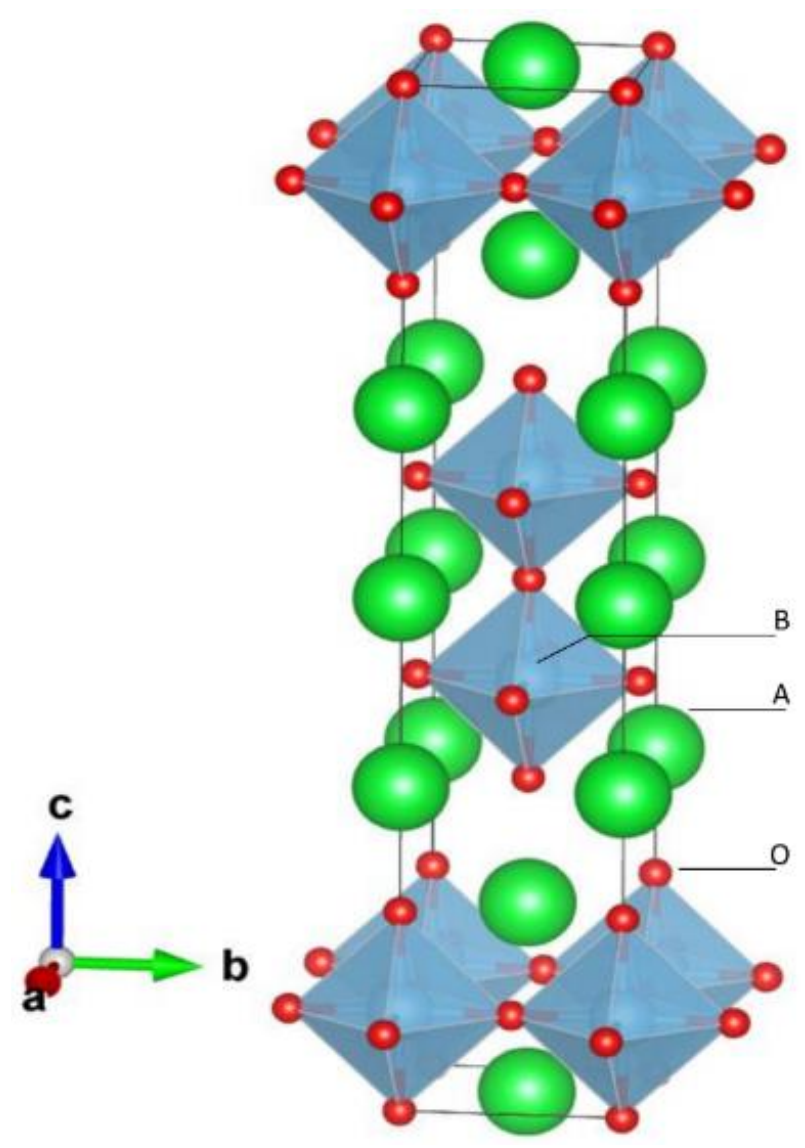

Figure 4. Another perovskite-related structure is the Ruddelsden Popper structure.

The layered perovskite family contains several polar and ferroelectric materials in contrast to bulk $\mathrm{ABO}_{3}$ perovskites. The (100)-oriented 2D perovskites are by far the most abundant class, and have been explored for a wide variety of cation templates. The geometrically planar inorganic-organic interface of the (100)-oriented layers not only allows the incorporation of a plethora of "spacer" cations between the 2D perovskites, but it also allows for the template "build-up" of the perovskite itself, which self-assembles in a layer-by-layer fashion between the spacers. These modular multilayered structures were first discovered in the oxide perovskites, where they were used to expand extended homologous series $[19,23]$. Following the oxide perovskite nomenclature, the (100)-oriented oxide perovskites can be further categorized as the Ruddlesden Popper (RP) phases [24,25], the Dion Jacobson (DJ) phases [24,25], and the Aurivillius phases [26,27], as shown in Figure 5, [28] where their general formulae can be written as $A_{2}^{\prime} A_{n-1} B_{n} O_{3 n+1}$, $\mathrm{A}^{\prime} \mathrm{A}_{\mathrm{n}-1} \mathrm{~B}_{\mathrm{n}} \mathrm{O}_{3 \mathrm{n}+1}$ and $\left(\mathrm{Bi}_{2} \mathrm{O}_{2}\right)\left(\mathrm{A}_{\mathrm{n}-1} \mathrm{~B}_{\mathrm{n}} \mathrm{O}_{3 \mathrm{n}+1}\right)$, respectively.

In the case of halide perovskites, most of these structure types have been realized, with the exception of the Aurivillius phases. It is entirely possible, however, that such layers can be formed using less reactive rock-salt-type layers, such as $\left(\mathrm{Ba}_{2} \mathrm{~F}_{2}\right)^{2+}$. As in the case of oxide perovskites, as well as in the case of halide perovskites, the nature of the spacer cation is important. Already, from the expression of the chemical formula, it is evident that the charge of the spacer cation defines the structural types of $2 \mathrm{D}$ perovskites. Nevertheless, both RP and DJ classes exist for the halide family, having the general formula of $\mathrm{A}_{2}^{\prime} \mathrm{A}_{n-1} \mathrm{~B}_{n} \mathrm{X}_{3 \mathrm{n}+1}$ and $\mathrm{A}^{\prime} \mathrm{A}_{\mathrm{n}-1} \mathrm{~B}_{\mathrm{n}} \mathrm{X}_{3 \mathrm{n}+1}\left(\mathrm{~A}^{\prime}=\right.$ interlayer "spacer" cation). 


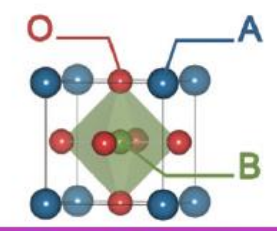

Cubic $\mathrm{ABO}_{3}$ Aristotype

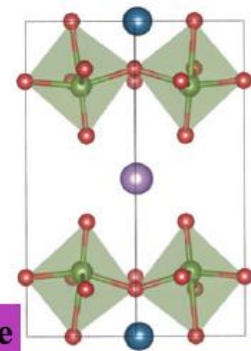

$\mathbf{A}^{\prime}\left[\mathbf{A}_{\mathrm{n}-1} \mathbf{B}_{\mathrm{n}} \mathbf{O}_{3 \mathrm{n}+1}\right]$

Dion Jacobson
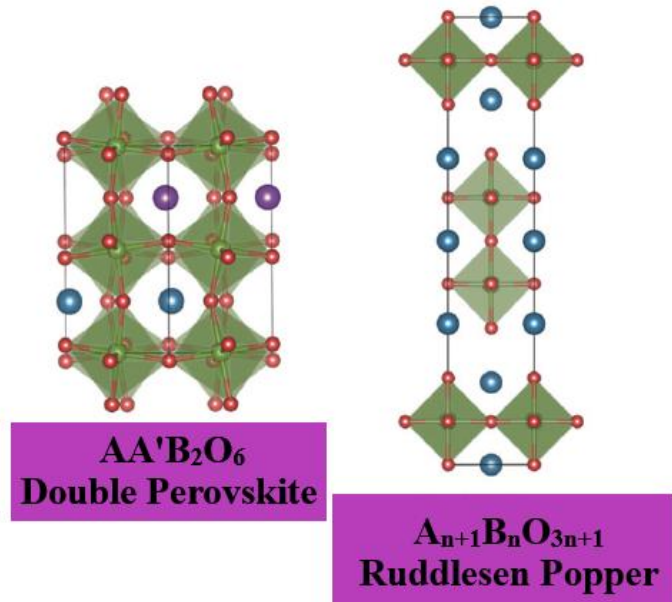

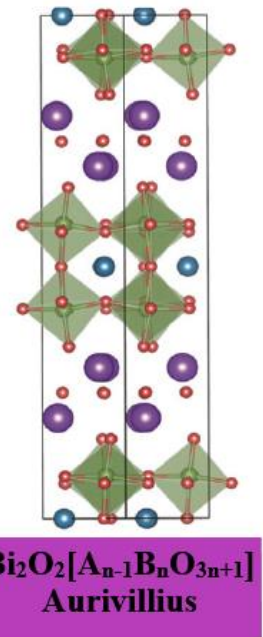

Figure 5. Layered perovskites-derived from the cubic $\mathrm{ABO}_{3}$ aristotype-are discussed in this perspective. In the Dion Jacobson phases, $\mathrm{A}^{\prime}$ is usually an alkali cation, but can also be a transition metal-halide complex, e.g., $(\mathrm{MnCl})^{+}$. In the A-site ordered double perovskites, $\mathrm{A}^{\prime}$ is chemically different from $\mathrm{A}$. The perovskite blocks are interleaved between $\left[\mathrm{Bi}_{2} \mathrm{O}_{2}\right]^{2+}$ layers in the Aurivillius phases. Adapted from Refs. [26,27] with permission from the European Society for Photobiology, the European Photochemistry Association, and The Royal Society of Chemistry.

\section{Formability versus Thermodynamic Stability}

Recently, Talapatra et al. [29] studied the relationship between two key properties governing the stability of single and double perovskites. The formability stands for the practical ability to synthesize a compound, whereas the thermodynamic stability stands for the thermodynamic preference to form a given structure or polymorph among several other possible crystal structures. The data set contains information from the literature which have been reported from experimental research as well as from DFT calculations. It consisted of 1505 simple oxide perovskites $\mathrm{ABO}_{3}$ and 3469 double-oxide perovskites $\mathrm{A}_{2} \mathrm{~B}^{\prime} \mathrm{BO}_{6}, \mathrm{AA}^{\prime} \mathrm{B}_{2} \mathrm{O}_{6}$ and $\mathrm{AA}^{\prime} \mathrm{BB}^{\prime} \mathrm{O}_{6}$, sampling a limited chemical space within the periodic table. They subsequently built machine learning classification models to screen and identify novel stable oxide perovskites. One of the most important finding is that they succeeded to make a clear difference between the perovskite's formability and the thermodynamic stability and to relate these two stability measures to the elemental properties of constituent chemical elements.

The formability of perovskites relies on geometrical consideration based on the ionic radii of the perovskites as well details in the sections above. However, this formability metric, although popular, does not inform us on whether the perovskite structure is the most favorable compared to other possible crystal structure, here is where the importance of thermodynamic stability arises. Under certain conditions, including temperature, pressure or variation in chemical potentials, some other crystal structures of polymorphs might be more stable than the perovskite one, even if they are favorably formable. The distance from the convex hull, also called $\Delta E_{h}$, might be a better thermodynamic stability measurement. Authors [29] have used the threshold of $\Delta E_{h} \leq 50 \mathrm{meV}$ as the limit that defines the cubic thermodynamic stability of the oxide perovskite, which is a value that is highly accepted by the community $[30,31]$. Using a random forest classification algorithm, Talapatra et al. [29] determined the most elemental features governing both stability metric and generated a very good accuracy predictive model for both stability metrics. Figure 6a shows an interesting finding within a plot of the energy above the hull as a function of the geometrical tolerance factor for the groups of materials that fulfill both the formability and stability criteria. One might notice that below the $\Delta E_{h}=50 \mathrm{meV}$, dashed line lies a high population of perovskite material $(66 \%)$, whereas the prevalence on non-perovskites is rather rare. Nevertheless, a non-negligible fraction of the compounds was excluded from the thermodynamic stability because of their high energy above the 
hull. Taking $\Delta E_{h}<400 \mathrm{meV}$ as a threshold appears to give more reliable classifications of the compounds, as also demonstrated from the histogram of incidence (frequency) of perovskites and non-perovskites within $\Delta E_{h}$ bins of $50 \mathrm{meV}$ each. The histogram indicates that up to $\Delta E_{h}=400 \mathrm{meV}$ compounds crystalizing in the perovskite structure are dominant, as shown in Figure $6 \mathrm{~b}$.

(a)

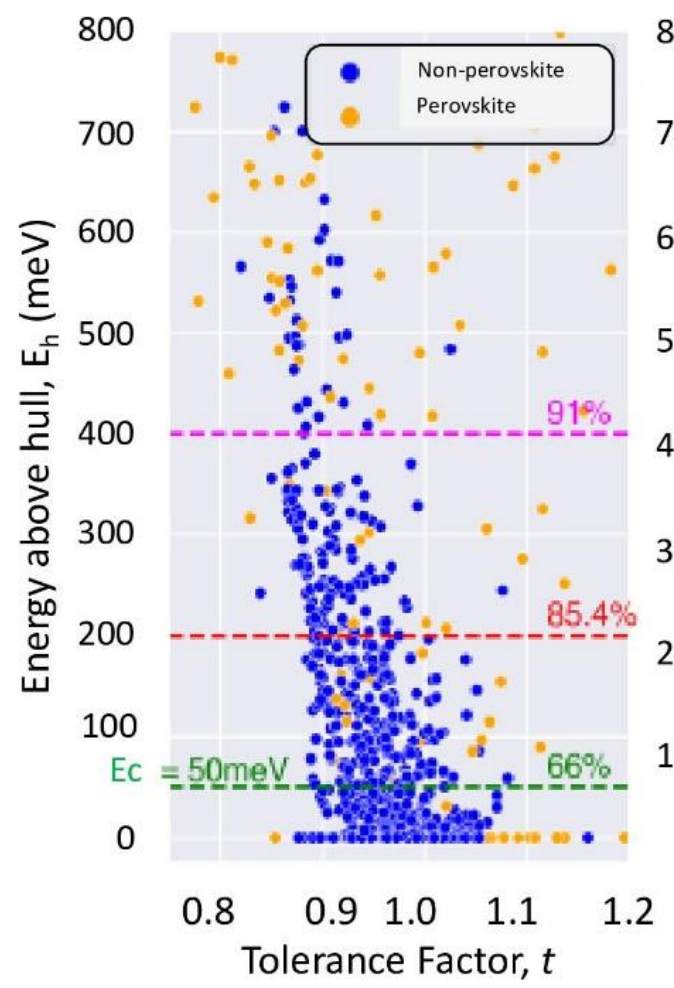

(b)

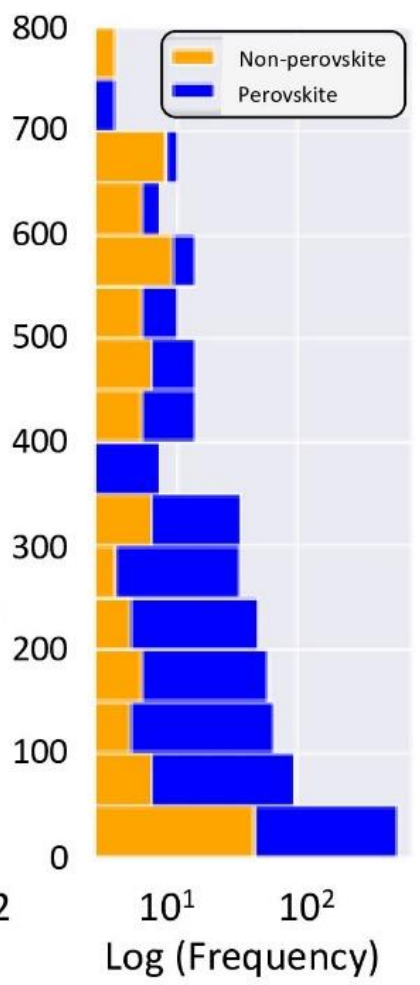

Figure 6. (a,b) Energy above hull $\left(\Delta E_{h}\right)$ in $\mathrm{meV}$ as a function of tolerance factor $(t)$ for candidate materials identified as stable and formable. Reproduced with permission from Ref. [29].

Hence, the cubic thermodynamic threshold of $\Delta E_{h} \leq 50 \mathrm{meV}$ might not be a reliable threshold for the metastability of oxide perovskite because it does account for stability enhancements due to octahedral tilts and octahedral deformation and elongations. It is concluded that the thermodynamic cubic stability must be selected carefully and should be tuned properly to include lower symmetry phases as well. This study and previous studies constitute very interesting advances in the prediction of novel oxide perovskites for targeted applications while taking into account their stability and formability prior to recommending their experimental synthesis in the laboratory.

\section{Typical Properties of Perovskite Oxides}

Perovskite oxides have a diverse plethora of properties because of their different compositions and structures. In $\mathrm{BaTiO}_{3}$-based oxides, and in $\mathrm{Ba}_{2} \mathrm{YCu}_{3} \mathrm{O}_{7}$, perovskite oxides exhibit ferroelectricity and superconductivity, respectively. Several perovskite oxides also exhibit substantially greater electric conductivity, ionic conductivity, and mixed ionic conductivity than many metals. For use in solid oxide fuel cells (SOFC), perovskite oxides have been preferred, with components based on differences in electrical conduction [32]. Table 2 lists the properties of several common perovskite oxides. Perovskite oxides take on several feature properties, such as ferroelectricity, magnetism, superconductivity, and catalysis. 
Table 2. Typical perovskite oxide properties.

\begin{tabular}{cc}
\hline Typical Properties & Typical Compound \\
\hline Ferromagnetism & $\mathrm{PdTiO}_{3}, \mathrm{BaTiO}_{3}$ \\
\hline Electrical conductivity & $\mathrm{ReO}_{3}, \mathrm{SrFeO}_{3}, \mathrm{LaCoO}_{3}, \mathrm{LaNiO}_{3}, \mathrm{LaCrO}_{3}$ \\
\hline Superconductivity & $\mathrm{La}_{0.9} \mathrm{Sr}_{0.1} \mathrm{CuO}_{3}, \mathrm{YBa}_{2} \mathrm{Cu}_{3} \mathrm{O}_{7}, \mathrm{HgBa}_{2} \mathrm{Ca}_{2} \mathrm{Cu}_{2} \mathrm{O}_{8}$ \\
\hline Piezoelectricity & $(\mathrm{Bi}, \mathrm{Na}) \mathrm{TiO}_{3}, \mathrm{~Pb}\left(\mathrm{Zr}, \mathrm{Ti}_{3} \mathrm{O}_{3}\right.$ \\
\hline Magnetism & $\mathrm{LaMnO}_{3}, \mathrm{LaFeO}_{3}, \mathrm{La}_{2} \mathrm{NiMnO}_{6}$ \\
\hline Ion conductivity & $\mathrm{BaZrO}_{3}, \mathrm{SrZrO}_{3}, \mathrm{BaCeO}_{3}, \mathrm{La}(\mathrm{Ca}) \mathrm{AlO}_{3}, \mathrm{CaTiO}, \mathrm{La}(\mathrm{Sr}) \mathrm{Ga}(\mathrm{Mg}) \mathrm{O}_{3}$ \\
\hline Electrode materials & $\mathrm{La}_{0.8} \mathrm{Ca}_{0.2} \mathrm{MnO}_{3}, \mathrm{La}_{0.6} \mathrm{Sr}_{0.4} \mathrm{CoO}_{3}$ \\
\hline Catalytic properties & $\mathrm{LaCoO}_{3}, \mathrm{BaCuO}_{3}, \mathrm{LaMnO}_{3}$ \\
\hline
\end{tabular}

\subsection{Dielectric Properties}

Ferroelectricity, piezoelectricity, electrostricity, and pyroelectricity, which are important electroceramic characteristics, are special properties of dielectric materials. $\mathrm{BaTiO}_{3}$, $\mathrm{PdZrO}_{3}$, and their doped compounds are all well known for their ferroelectricity. It has been investigated in depth that there is a close correlation between the ferroelectric activity of $\mathrm{BaTiO}_{3}$ and its crystal structure. $\mathrm{BaTiO}_{3}$ can be present in three distinct phases: monoclinic, tetragonal, and cubic. The transition between the phases occurs with a rise in temperature. As a matter of fact, above $303 \mathrm{~K}$, cubic $\mathrm{BaTiO}_{3}$ is obtained, which is non-ferroelectric in nature. Crystal structure anisotropy may explain $\mathrm{BaTiO}_{3}$ 's high dielectric constant.

\subsection{Electrical Conductivity and Superconductivity}

The superconductivity of perovskite oxides is the most famous characteristic among the other features. In La-Ba- $\mathrm{Cu}-\mathrm{O}$ perovskite oxide, superconductivity was found and introduced for the first time by Bednorz and Müller in 1984 [33]. After their report, much attention was drawn towards high-temperature superconductors, particularly $\mathrm{Cu}$-based oxides, which were given much attention after their report. Other than $\mathrm{Cu}$-based oxides, data have been reported on numerous superconducting oxides with different $\mathrm{A}$-site cations. On the B-site, $\mathrm{Cu}$ presence is crucial for superconductance, however. $\mathrm{YBa}_{2} \mathrm{Cu}_{3} \mathrm{O}_{7}$ system [33] and $\mathrm{Bi}_{2} \mathrm{Sr}_{2} \mathrm{Ca}_{2} \mathrm{Cu}_{3} \mathrm{O}_{10}$ system [34] superconductors were reported in 1987 and 1988 , respectively. The critical temperature of the superconducting transition $\left(T_{c}\right)$ in the $\mathrm{HgBa}_{2} \mathrm{Ca}_{2} \mathrm{Cu}_{3} \mathrm{O}_{8+\delta}$ system has been further increased to 130-155 K [33]. All superconducting oxides at high temperatures are cuprites; therefore, superconductivity is specifically correlated with the layers of copper oxide, as well as the $T_{c}$ (critical superconductivity temperature), and the values are summarized in Table 3:

Table 3. Superconductivity correlated with the number of $\mathrm{Cu}-\mathrm{O}$ layers.

\begin{tabular}{cc}
\hline Number of Layers & $\mathbf{T}_{\mathbf{c}} \mathbf{( K )}$ \\
\hline 1 & 30 \\
\hline 2 & 90 \\
\hline 3 & 110 \\
\hline 4 & 120 \\
\hline
\end{tabular}

A further rise in $\mathrm{Cu}-\mathrm{O}$ layer numbers is predicted to contribute to higher $\mathrm{T}_{\mathrm{c}}$ values. Five or more copper oxides layers have not been effective until now due to the low chemical stability. $\mathrm{YBa}_{2} \mathrm{Cu}_{3} \mathrm{O}_{7}$ is amongst the most significant high- $\mathrm{T}_{\mathrm{C}}$ superconductor systems, and extensive studies have been already carried out on its crystal structure. In addition, the nonstoichiometric oxygen content is a key factor in high $T_{c}$. If the $d$ value is less than 0.5 , 
$\mathrm{YBa}_{2} \mathrm{Cu}_{3} \mathrm{O}_{7}$ crystalizes in a superconductive orthorhombic structure, whereas for $\mathrm{d}>0.5$, it is tetragonal structure, which is non-superconducting.

In addition to the superconductivity, there are numerous perovskite oxides with a high electronic conductivity, even close to that of metals such as $\mathrm{Cu} . \mathrm{LaCoO}_{3}$ and $\mathrm{LaFeO}_{3}$ are the most common examples of perovskite oxides, whereas $\mathrm{LaMnO}_{3}$ is now widely used in SOFCs as a cathode. Superior hole conductivity as high as $\sigma=100 \mathrm{~S} / \mathrm{cm}$ is exhibited by these perovskite oxides, which is attributed to the of excess oxygen [35,36]. Doping at the aliovalent cation site also leads to considerably improve the electrical conductivity, because the charge compensation creates an increased number of mobile charge carriers.

\subsection{Catalytic Activity}

Perovskite oxides have been investigated in depth as catalysts for different reactions, due to the diversity of components and their high chemical stability. Two types of researchtrends are indicated on this front. The first one is related to develop catalysts for oxidation as a substitute to the precious metals catalysts, or oxygen-activated catalysts. The second one is to consider the perovskite as an active site platform. The stable nature of perovskite enables compounds to be prepared with an exceptional element of valences or with an enhanced degree of oxygen deficiency. It has been reported that perovskite oxides provide a high catalytic activity because there are a lot of oxygen vacancies, and it also depends -although partly- on the high surface activity to reduce oxygen or to activate it. From the examination of different catalytic reactions, environmental catalysis has gained a special attention (e.g., catalysts for the exhaust gas cleaning of automobiles). Initially, perovskite oxides, comprising $\mathrm{Fe}, \mathrm{Cu}, \mathrm{Mn}$ or $\mathrm{Co}$, were known to increase activity at higher temperatures than that obtained from a direct $\mathrm{NO}$ decomposition [37-39]. The process related to $2 \mathrm{NO}=\mathrm{N}_{2}+\mathrm{O}_{2}$, where a direct $\mathrm{NO}$ decomposition takes place, is an ideal reaction in the catalysis. Easy separation of oxygen at the surface as a reaction product has a vital role because perovskite oxides are active due to oxygen deficiency at high temperatures. Doping is noted to be highly successful in enhancing the NO decomposition operations. It has been identified that the perovskite $\mathrm{Ba}(\mathrm{La}) \mathrm{Mn}(\mathrm{Mg}) \mathrm{O}_{3}$, in a rich environment of oxygen, can obtain a fairly high NO decomposition rate (up to 5\%) [38-40].

Perovskite oxides are also used as catalysts for automobiles for the self-regeneration of precious metals in a usage ambience without auxiliary treatment $[41,42]$. To date, for the removal of NO, CO and non-combusted hydrocarbons, three-way catalysts (TWC) and $\mathrm{Pd}-\mathrm{Rh}-\mathrm{Pt}$ catalysts have been used widely. The fine particle catalyst with a high volume-to-surface ratio must lower the needed quantity of precious metals. Even then, they are not stable under operational circumstances and can sinter easily, and the catalyst is therefore deactivated. The redox properties of perovskite oxides were suggested in order to preserve a high degree of dispersion, i.e., palladium is oxidized under oxidation conditions and stays as $\mathrm{LaFe}_{0.57} \mathrm{Co}_{0.38} \mathrm{Pd}_{0.05} \mathrm{O}_{3}$ where palladium nanoparticles (1-3 nm) are deposited under reduced conditions. Such oxidation and reduction of the catalyst lead to partial Pd substitution and deposition from the perovskite base, thereby retaining a high degree of Pd dispersion. This was considered to be significantly successful in enhancing long-term $\mathrm{Pd}$ stability while removing $\mathrm{NO}_{\mathrm{x}}, \mathrm{CO}$ and hydrocarbons from the gas exhausted. By displaying the catalyst in oxidation and reduction environments, high-dispersion status $\mathrm{Pd}$ can be restored. Therefore, this catalyst is often termed as an intelligent catalyst. Such character is attributed to the perovskite crystal structure stability. In the lattice, the redox couples of another cation naturally accommodate for the charge. Photocatalysts for water splitting are another important application of perovskite oxides. The use of ultraviolet light among catalysts for water splitting into $\mathrm{H}_{2}$ and $\mathrm{O}_{2}$ is observed to have an increased activity of perovskite oxide based on Ta and Na.

\subsection{Photocatalytic Activity}

It is possible to use photo-excited electrons and holes to split $\mathrm{H}_{2} \mathrm{O}$ into $\mathrm{H}_{2}$ and $\mathrm{O}_{2}$, and this process gains more attention in solar energy conversion into hydrogen. Several 
inorganic catalysts for water splitting have been investigated as water photocatalysts, especially $\mathrm{Pt} / \mathrm{TiO}_{2}$ as a well-known photocatalytic inorganic semiconductor. In the photocatalytic water-splitting reaction, the Ta-based oxide is normally active. The Ta-based perovskite oxide, $\mathrm{ATaO}_{3}$ ( $\mathrm{A}=$ alkaline cation), specifically displays high water-splitting activity [43]. The A cation strongly affects the activity because the crystal structure is linked to the oxide's electronic configuration. The Ta-O-Ta bond angles are $143^{\circ}\left(\mathrm{LiTaO}_{3}\right), 163^{\circ}$ $\left(\mathrm{NaTaO}_{3}\right)$, and $180^{\circ}\left(\mathrm{KTaO}_{3}\right)$. The bonding angle close to $180^{\circ}$ means that excited energy migration easily occurs in the crystal and results in a smaller band gap. Hence, $\mathrm{LiTaO}_{3}<$ $\mathrm{NaTaO}_{3}<\mathrm{KTaO}_{3}$ is the delocalization order of excited energy and vice versa for these band gaps, as shown in Figure 7. Table 4 presents the photocatalytic water-splitting activities of pure water into $\mathrm{H}_{2}$ and $\mathrm{O}_{2}$ on alkaline tantalite photocatalysts with and without $\mathrm{NiO}$ cocatalysts. When $\mathrm{NiO}$ cocatalysts were loaded, $\mathrm{NaTaO}_{3}$ photocatalysts demonstrated the highest photocatalytic activity. In this case, excessive amounts of $\mathrm{Na}$ in the starting material were necessary to demonstrate high activity. The photocatalyst $\mathrm{NaTaO}_{3}$ 's conduction band level was higher than the $\mathrm{NiO}$ level $(-0.96 \mathrm{eV})$, as shown in Figure 7 [43]. In addition, in the $\mathrm{NaTaO}_{3}$ crystal, the excited energy was delocalized. Therefore, the photogenerated electrons in the $\mathrm{NaTaO}_{3}$ photocatalyst's conductive band were capable of passing to the $\mathrm{NiO}$ cocatalyst's conduction band of an active site for $\mathrm{H}_{2}$ generation, leading to an increase in the separation of the charge. Hence, even without special pretreatment, $\mathrm{NiO}$ loads were successful for the $\mathrm{NaTaO}_{3}$ photocatalyst.

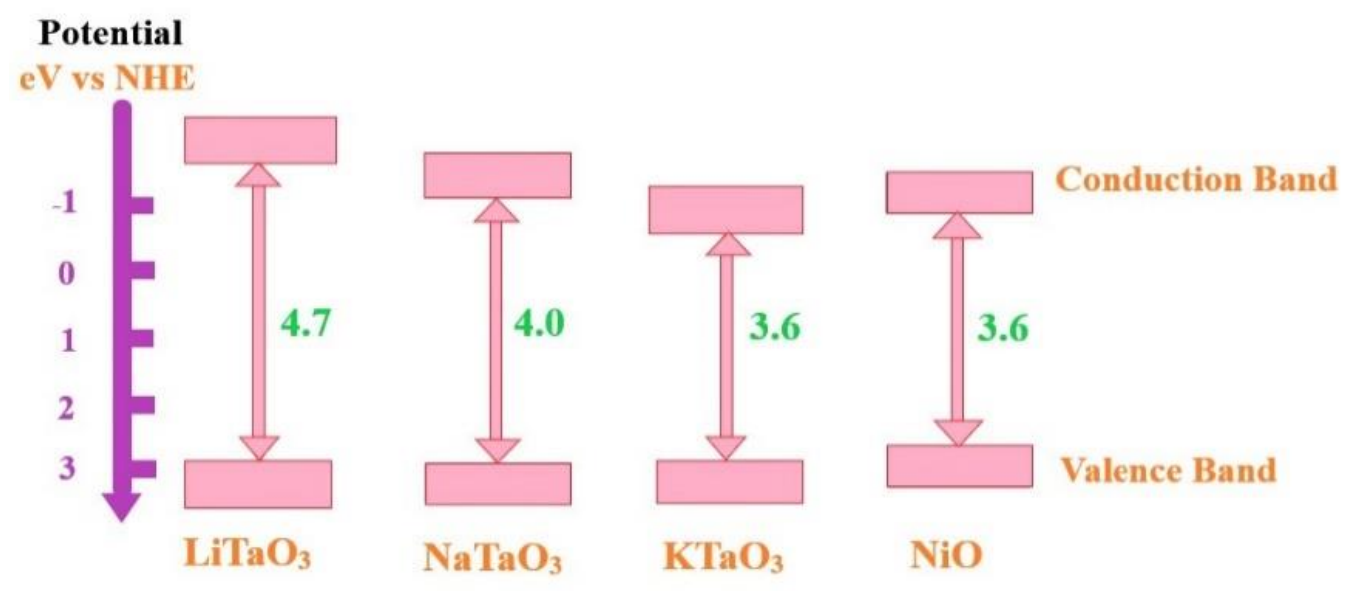

Figure 7. Band diagram of a hydrogen electrode-based alkali tantalates $\mathrm{ATaO}_{3}(\mathrm{~A}=\mathrm{W} \mathrm{Li}, \mathrm{Na}$, and $\mathrm{K})$ band structures with perovskite-type structures. Adapted from Ref. [43].

Table 4. Appropriate perovskite oxide materials for use in SOFCs.

\begin{tabular}{cc}
\hline Component & Typical Materials \\
\hline Interconnector & $\mathrm{La}(\mathrm{Ca}) \mathrm{CrO}_{3}$ \\
\hline Anode & $\mathrm{SrTiO}_{3}, \mathrm{La}_{1-x} \mathrm{Sr}_{x} \mathrm{Cr}_{1-y} \mathrm{M}_{y} \mathrm{O}_{3}(\mathrm{M}=\mathrm{Mn}, \mathrm{Fe}, \mathrm{Co}, \mathrm{Ni})$, \\
\hline Electrolyte & $\mathrm{La}(\mathrm{Sr}) \mathrm{Ga}(\mathrm{Mg}) \mathrm{O}_{3}\left(\mathrm{O}^{2-}\right), \mathrm{SrZrO}_{3}\left(\mathrm{H}^{+}\right), \mathrm{Ba}_{2} \mathrm{In}_{2} \mathrm{O}_{5}\left(\mathrm{O}^{2-}\right), \mathrm{BaCeO}_{3}\left(\mathrm{H}^{+}\right)$, \\
$\mathrm{BaZrO}_{3}\left(\mathrm{H}^{+}\right)$,
\end{tabular}

\section{Multiferroic Oxide Thin Films}

Multiferroics jargon applies to materials where two or more ferroelectric orders coexist, such as anti-ferromagnetism, ferroelectricity, and ferroelasticity. Between ferroic orders, strong coupling can yield substantial features, particularly magnetoelectric effects, which also allow an electric field to control electric polarization by a magnetic field as well as its magnetization. It is a consequence of great achievements in physics and science behind the various new fields of multifunctional computers and memory [44-47]. 


\subsection{Synthesis of Multiferroic Thin Films and Strain Engineering}

An undeniable fact is that the development of tools used to deposit thin multiferroic films has been empowered because of the breakthroughs in thin film deposition techniques $[48,49]$. In contrast to the conventional approaches, the characteristics of thin multiferroic films could be improved with the proper optimization of the synthesis parameters.

In the 1960s, for instance, BFO was investigated thoroughly. However, due to the leakage problems linked to its poor crystal quality, its spontaneous polarization yielded only a few $\mu \mathrm{C} / \mathrm{cm}^{2}$ [50-52]. This dilemma was finally resolved by quality thin-film growth in 2003, and was one of the landmarks in the multiferroics field with the use of pulsed laser deposition (PLD) [53].

Efficient thin-film growth is the starting point and the cornerstone of the innovation and development of most electronic devices, but it brings many complicating factors such as the strain in the substrate, surface conditions, degree of impurities, structure imperfections, etc. Too much leakage current, for instance, may affect the ferroelectricity measurement; in addition, spin canting can be incorporated due to the surfaces and interfaces and consequently affects the magnetism. Therefore, it is essential that techniques for keeping or enhancing thin multiferroic films properties are secured.

To fabricate multiferroic thin films, various SOTA physical deposition techniques have been used, such as PLD, sputtering and molecular beam epitaxy (MBE) as well as in chemical deposition paths, such as sol-gel, metal-organic chemical vapor deposition (MOCVD), and spin coating. PLD is the most commonly applied technique by researchers, especially for the investigation of new materials and heterostructures. PLD's inherent benefit is that the growth process occurs far from optimum; therefore, it is capable of maintaining complicated stoichiometry, which is necessary for multi-element compound growth. In addition, PLD, which is equipped with high-energy electron diffraction (RHEED) reflecting on-site, facilitates efficient film thickness control at the level of the unit cell [53], which is essential for enhanced epitaxial thin films synthesis. Unlike MBE, PLD requires very low energy $(\sim 1 \mathrm{eV})$ thermal atomic beam generation, which is appropriate for highly perfect thin multiferroic film fabrication as well as other complex oxides [53]. PLD and MBE can fabricate superior quality films, but they are costly when applying for mass production. For mass production, sputtering techniques are extensively used, namely, magnetron sputtering, ion-beam sputtering, and off-axis sputtering [54]. For the fabrication of high-grade thin oxide films with the required stoichiometry of oxygen, accurate reactive gas control, in particular $\mathrm{O}_{2}$ or $\mathrm{Ar} / \mathrm{O}_{2}$ mixtures, is essential. For thin-film fabrication on large areas with low costs, sol-gel spin-coating is also an appropriate and cost-effective chemical process.

The films obtained are, therefore, mostly in polycrystal or textured structures, and the sample thicknesses and morphologies are challenging to tweak. Consequently, in the electronics industry, MOCVD has commonly been used, providing remarkable prospects for multiferroic film deposition owing to multiple features, including outstanding film homogeneity throughout large areas, significantly higher deposition rates, and compliance with current integrated circuit technologies [55]. However, limited metal-organic sources of complex oxides are available. In a few recent articles, more knowledge on the growth of thin films with ferroelectric and multiferroic oxides can be extracted [56-58].

\subsection{Bi-Containing Multiferroic Thin Films \\ (i). $\mathrm{BiFeO}_{3}$}

One of the most promising stories in the field of multiferroic research is $\mathrm{BiFeO}_{3}$, which demonstrates ferroelectric and magnetic room temperature orders $\left(\mathrm{T}_{\mathrm{C}}=830^{\circ} \mathrm{C}\right.$ and $\mathrm{T}_{\mathrm{N}}=370^{\circ} \mathrm{C}$ ). The development of ferroelectric polarization is motivated by more polarizable Bi lone pair ordering, whereas in adjacent $\mathrm{Fe}$ and $\mathrm{O}$ ions, super-exchange contributes to the antiferromagnetic order of the G-type. With lattice parameters of $a_{h e x}=5.58 \AA$ and $c_{\text {hex }}=13.90 \AA$, bulk BFO is a rhombohedral (space group: R3c), whereas a lattice parameter $\mathrm{a}=3.965 \AA$ is for its perovskite-type unit cell $[59,60]$. 


\section{(ii). $\mathrm{BiMnO}_{3}(\mathrm{BMO})$}

$\mathrm{BMO}$ is a distinctive multiferroic material of a ferromagnetic $\left(\mathrm{T}_{\mathrm{FM}}=105 \mathrm{~K}\right)$ and a ferroelectric $\left(\mathrm{T}_{\mathrm{FE}}=770 \mathrm{~K}\right)$ ground state with simultaneous polarization $\left(\mathrm{P} \sim 16 \mu \mathrm{C} / \mathrm{cm}^{2}\right)$ and magnetization ( $\mathrm{M} \sim 3.6 \mu \mathrm{B} / \mathrm{Mn})$ [61]. Similarly to BFO, the ferroelectric state in $\mathrm{BMO}$ is activated by the stereochemical behavior of the lone pairs of $\mathrm{Bi} 6 \mathrm{~s}^{2}$, whereas the ferromagnetism emanates from the ferromagnetic superexchange interplay between $\mathrm{Mn}^{3+}$ ions. For bulk BMO single-crystal synthesis, high pressure is needed; however, epitaxial stability in thin films may solve this challenge [62]. Its magnetic property is highly sensitive to growing parameters related to the Bi vacancy and the substrate strain effect [62-64].

(iii). $\mathrm{BiCrO}_{3}(\mathrm{BCO})$

In contrast to $\mathrm{BFO}$, there are fewer researched data sets available for $\mathrm{BCO}$ thin films [65-67]. In BCO, a G-type antiferromagnetic ground state with distortion of the antiferroelectric structure was first hypothetically presumed by Hill [65]. Piezoelectric behavior and controllable dielectric constant were confirmed by Murakami et al. [67] in an epitaxial BCO thin film developed on the $\mathrm{LaAlO}_{3}(\mathrm{LAO})$ substrate where weak ferromagnetism occurs at low temperatures. Another characteristic perovskite multiferroic material is $\mathrm{BCO}$, with a large $\mathrm{A}$-site $\mathrm{Bi}_{3} \mathrm{p}$, where antiferroelectricity and poor parasitic ferromagnetism have been shown $[67,68]$.

\section{(iv). Bi-Based Ordered Double Perovskites}

Perovskites such as $\mathrm{BiFe}_{0.5} \mathrm{Mn}_{0.5} \mathrm{O}_{3}$ and $\mathrm{BiFe}_{0.5} \mathrm{Cr}_{0.5} \mathrm{O}_{3}$ are known as ordered double perovskites. These are Bi-based transition metal perovskites, i.e., $\mathrm{BiMO}_{3}$, where $\mathrm{M}=\mathrm{Fe}$, $\mathrm{Mn}, \mathrm{Cr}$, etc., were hypothesized to be intriguing materials with multiferroic properties for which significant spontaneous polarization and ferromagnetism could subsequently be experienced [56,65].

\subsection{Multiferroic Rare-Earth Manganites}

Rare-earth (RE) manganites are a fascinating class of compounds that seem to have a hexagonal structure if the $\mathrm{R}$ ionic radius is small ( $\mathrm{P} 63 \mathrm{~cm}$, from Sc, $\mathrm{Y}$, and $\mathrm{Ho}$ to $\mathrm{Lu}$ ), or if the ions are large, an orthorhombic structure (Pnma, from Dy to La). Around $\mathrm{Y} / \mathrm{Ho}$, the overlap is shown in Figure 8 [69]. The latest investigations have shown that hexagonal manganites carrying a small ionic radius $\mathrm{R}$ can be converted into the orthorhombic phase using thin-film growth, high-pressure treatment, or soft chemical synthesis. Interesting physical properties have been revealed in the subsequently obtained orthorhombic phases. Conversely, by leveraging the epitaxial strain, the subsequently formed phase can also be converted back, and the related physical properties can be changed accordingly [70-72].

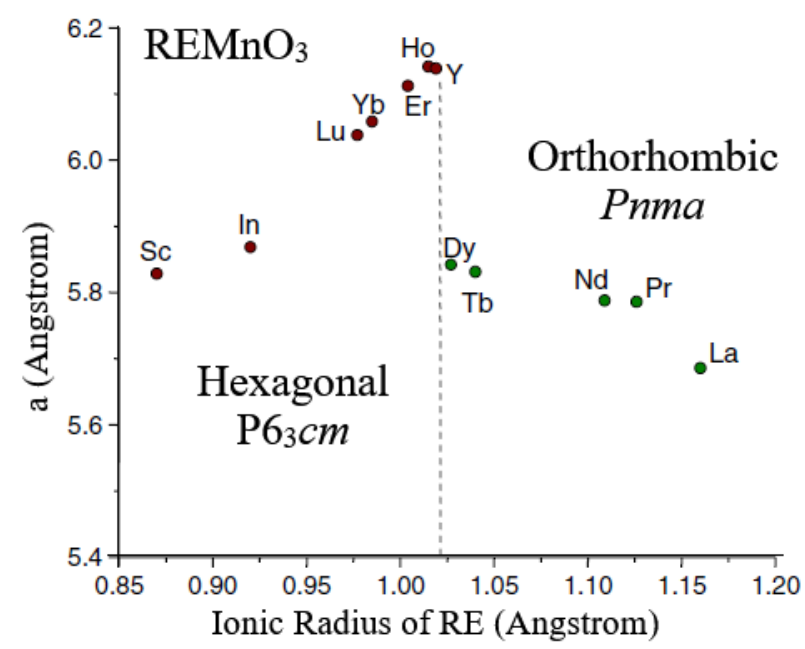

Figure 8. Evolution of the lattice structure in $\mathrm{REMnO}_{3}$ as a function of the size of the rare-earth (RE) element. Reprinted from Ref. [57]. 


\section{(i). Antiferromagnetic $\mathrm{REMnO}_{3}$}

Throughout the alternatively packed c axis, $\mathrm{YMnO}_{3}(\mathrm{YMO})$ with $\mathrm{MnO}_{5}$ trigonal bipyramids (distinct from $\mathrm{MnO}_{6}$ octahedrons in the perovskites) and $\mathrm{Y} 3 \mathrm{p}$ are the most investigated hexagonal $\mathrm{REMnO}_{3} . \mathrm{A}=6 \AA$ [11], and $\mathrm{c}=11 \AA$ [4], are the lattice parameters of YMO [58]. YMO's noticeable added benefit is that it comprises no volatile elements, such as $\mathrm{Bi}$ and $\mathrm{Pb}$. Therefore, due to the geometric constraint, hexagonal YMO spin configuration is hindered. By robust in-plane antiferromagnetic super-exchange interaction, the spins of $\mathrm{Mn}^{3+}$ are controlled in the $\mathrm{MnO}_{5}$ bipyramid layers (ab plane) and confined within the plane.

(ii). Orthorhombic $\mathrm{REMnO}_{3}$ with Spiral Spin Order (SSO)

In 2003, Kimura et al. [73] in 2003 were the first to report magnetic ferroelectricity regulations in TMO. Having $\mathrm{a}=5.2931 \AA, \mathrm{b}=5.8384 \AA$, and $\mathrm{c}=7.4025 \AA$ as lattice parameters, TMO has a perovskite crystal structure [69]. The breaking of spatial-inversion and time-reversal symmetries works synergistically in this material, and the intrinsic magnetic structure, i.e., SSO, produces ferroelectricity. Tens of magnetically activated multiferroic materials have been formulated so far, and two forms of SSO have been shown to be essential for spontaneous polarization production $[74,75]$.

\subsection{Other Multiferroic Thin Films}

The exploration for further high-performance multiferroic materials has been productive. One observation is provided here, i.e., $\mathrm{CuMO}_{2}(\mathrm{M}=\mathrm{Cr}, \mathrm{Mn}, \mathrm{Fe}$, or $\mathrm{Co})$ delafossite-type. The two-dimensional (2D) triangular crystal structure of this class of materials has $\mathrm{M}$ oxide magnetic layers and the cuprous oxide layers packed along the c axis. Due to the intrinsic multiferroicity induced by the frustrated spin configuration, these $2 \mathrm{D}$ triangular antiferromagnets have attracted a great deal of attention $[76,77]$. For $\mathrm{CuCrO}_{2}$, it was shown that the reversal of ferroelectric polarization could be precisely adjusted via electric and magnetic fields [78]. Multiferroic $\mathrm{CuMO}_{2}$ thin films have been identified, and UV-Vis-NIR measurements have been performed on these thin multiferroic films [79,80].

\subsection{Magnetism in Multiferroic Thin Films}

In most well-studied multiferroic materials such as BFO and TMO, the antiferromagnetic spin order coexisting with ferroelectricity does not contribute significantly to any macroscopic magnetic moment. Canting by the Dzyaloshinskii-Moriya interaction (DMI) of the AFM-aligned spins will lead to weak FM [81]. It is advantageous for applications involving multiferroic devices to improve the magnetism of these materials and to obtain significant purposeful magnetism. There are numerous published mechanisms in the literature for increasing magnetism in multiferroic oxide thin films. Most of the work in this regard has been performed on BFO. Holcomb et al. [82] found that the antiferromagnetic process in epitaxial BFO thin films is susceptible to strain and thickness, by integrating temperature- and angle-dependent dichroic measurements and spectroscopy. In thin films of $\mathrm{BFO} / \mathrm{LaAlO}_{3}$ with strong compressive strain, where the saturated magnetism and coercivity of the highly strained phase are approximately six times greater than those of the relaxed phase, analogous magnetic modulation has been found [70]. $\mathrm{BFO} / \mathrm{LaAlO}_{3}$ thin films have shown a small but definite spin glass (SG) transition [70,83]. Proportionally, strain may have a significant impact on the magnetic properties of BFO thin films. It is noticeable that for integration into functional devices, glassy magnetism would not be too strong in thin BFO films.

\section{Photovoltaic Effect in Multiferroic Thin Films as a Photoactive Layer}

In recent years, fascinating PV effects have been observed in thin films of BFO with patterned domains, due to which the resulting voltage is considerably larger than the bandgap (Figure 9) [84,85]. A ferroelectric-domain-based model has been proposed in attempt to elucidate this novel PV effect in BFO thin films $[85,86]$. The developed potential 
steps triggered by the polarization component will efficiently separate photo-generated electrons and holes. An overall electrical voltage across the sample would be produced by the aggregation of electrons/holes in the domain walls, possibly contributing to the observed open circuit photovoltage.

(a)

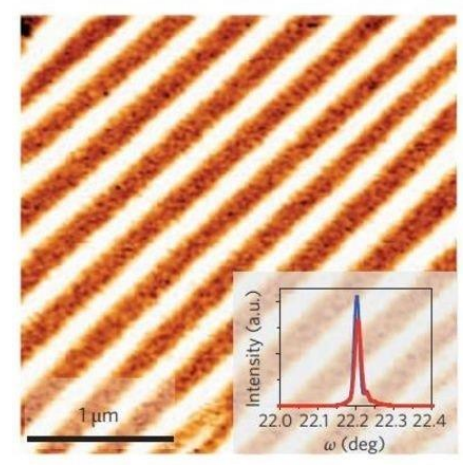

(c)

(e)
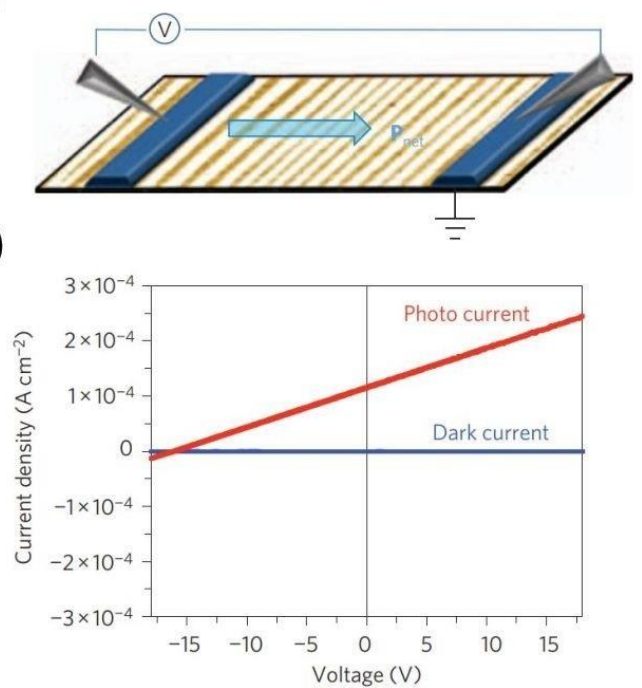

(b)

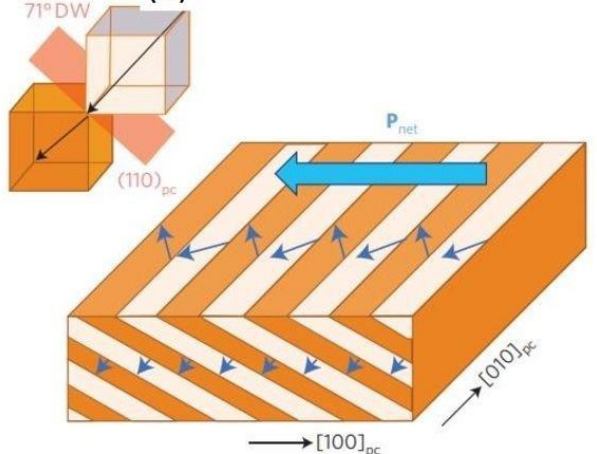

(d)

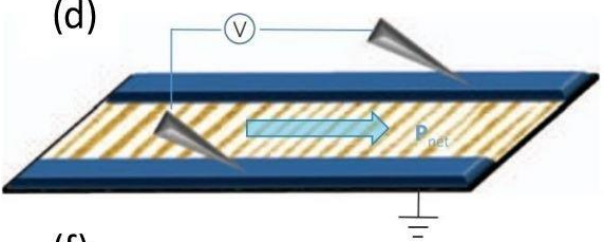

(f)

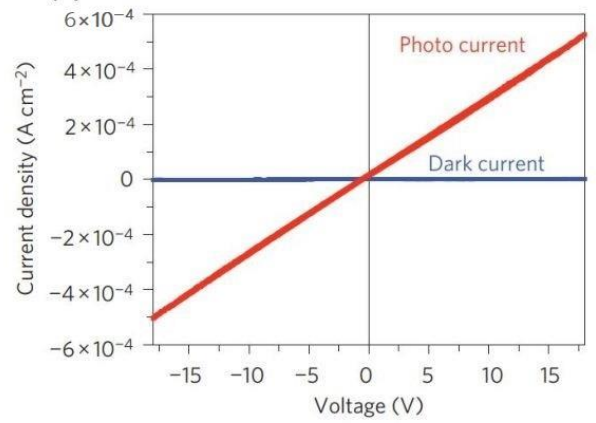

Figure 9. (a) Walls periodic arrays PFM image ( $71^{\circ}$ domain). (b) Schematic of the X-ray rocking curves along two orthogonal crystal axes are shown in the inset. Arrows indicate the ferroelectric polarization of different components. Representative illustrations of domain walls parallel (c) at (d) at right angles. The responsive measured I-V curves are perpendicular to the domain walls (e) and parallel to the domain walls (f). Reproduced with permission from Ref. [87].

PV effects without striped domains and even in bulk single-crystal monodomain were observed in BFO thin films by many groups [62-64,71,87]. Furthermore, without a regular domain configuration in conventional ferroelectrics, PV effect has also been detected [88-90]. Bhatnagar et al. conducted temperature-dependent PV effect measurements in BFO thin films with regard to the site of domain walls on the abnormal PV effect, and demonstrated that the bulk PV effect is the root cause [91], and showed a significant lasting PV effect in a strained BFO [72]. Yuan et al. [92] suggested a model to describe the PV effects in ferroelectric materials wherein the depletion region is altered by switching the polarization, after comparison with the typical PV effects in p-n/Schottky junctions, so that the polarization PV current and voltage directional dependence can be adjusted. The bulk photovoltaic effect is usually observed to be switchable with the reversal of polarization [87], which is implied to be due to the transition caused by the polarization between Ohmic and Schottky contacts and the defects of electromigration such as vacancies of oxygen [93]. Based on this concept, Guo et al. recently suggested a new type of non-destructive 
FeRAM device [94]. The fundamental concept is to use the short circuit current $\left(\mathrm{I}_{\mathrm{sc}}\right)$ or the open circuit voltage $\left(\mathrm{V}_{\mathrm{oc}}\right)$ to determine the polarization direction. The model device structure, where a positive (negative) $V_{\text {oc }}$ refers to the up (down) polarization, is shown in Figure 9. When the device is illuminated with light, both $\mathrm{V}_{\mathrm{oc}}$ and the polarization state can be read.

Kundys et al. [95] recently reported a fascinating phenomenon with respect to the lightinduced effect: by the illumination of light, the size of the BFO crystal can be controlled. Photostriction observations suggest the possibility of understanding mechanical, magnetic, electrical, and optical functionalities in monolithic multifunctional devices.

\section{Oxygen-Separating Membrane}

Perovskite oxides demonstrates electronic and oxide ionic conductivity of a greater degree, known as mixed conductors. Electronic conductivity in these, such as ion transfer, can be obtained naturally, because in mixed conductors, ions can be transferred without external circuits. Therefore, one of the useful applications of these mixed conductors is the oxygen-separation membrane.

Diffusivity for oxide ions is displayed in Figure 10 for typical perovskite oxides that can be used for oxygen permeation membranes [96,97]. It is reported that high oxide ion conductivity has been observed by Fe- or Co-based perovskite oxides. Therefore, it is predicted that their oxide ion permeability is high. The oxygen permeation rate is 1:05 mL/cm ${ }^{2}$ min at $1173 \mathrm{~K}$ of $\mathrm{Ba}_{0: 5} \mathrm{Sr}_{0: 5} \mathrm{Fe}_{0: 8} \mathrm{Co}_{0: 2} \mathrm{O}_{3}$ (BSCF) $(2 \mathrm{~mm}$ thickness) [97]. Across the membranes, identical oxygen partial pressure gaps appear; then, using the ion diffusivity and membrane thickness, the oxygen permeation rate can be calculated. As a result, as the membrane thickness decreases, the oxygen permeation rate should increase; however, the oxygen permeation rate is dependent on the membrane thickness when the thickness is high. However, as thickness decreases, the oxygen permeation rate becomes independent of membrane thickness due to surface reactions of oxygen dissociation. This means that when a high diffusivity of oxide ions in the bulk is needed, oxygen dissociation surface activity must also be high. The new uses for perovskite-related oxides make them very common for mixed conductors, and their applications for oxygen permeation membranes are also growing. There is a high interest in $\mathrm{K}_{2} \mathrm{NiF}_{4}$-type oxides in perovskite-related oxides due to their high oxygen deficiency. Thus, the ideal application might be the perfect blend of mixed conductors and catalytic reactions.

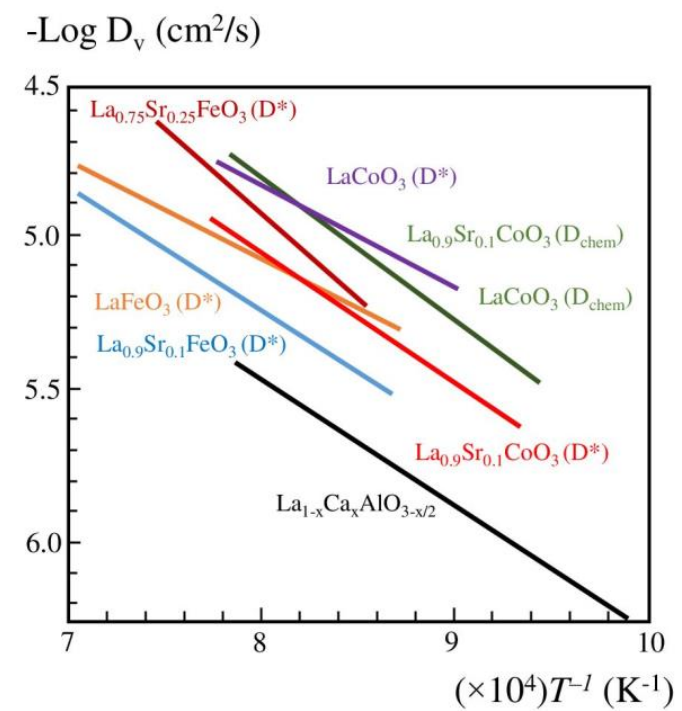

Figure 10. Diffusivity of oxygen ions in various perovskite oxides employed in an oxygen permeation membrane. $D^{*}, D_{v}$ calculated from the tracer diffusion coefficient; $D_{\text {chem }}, D_{v}$ calculated from the chemical diffusion coefficient. Adapted from Ref. [97]. 
For the separation of oxygen from the air, partial oxidation of $\mathrm{CH}_{4}$ was investigated with mixed perovskite conductors [98]. Partial oxygen pressure in $\mathrm{CH}_{4}$ is as low as $10^{-20}$ atm.; therefore, a high rate of oxygen permeation is obtained within partial $\mathrm{CH}_{4}$ oxidation conditions, and it has been stated, using $\mathrm{SrFe}_{0: 8} \mathrm{Co}_{0: 2} \mathrm{O}_{3}$ perovskite, that the oxygen permeation rate is $5 \mathrm{cc} / \mathrm{min} \mathrm{cm}{ }^{2}$ [99]. In a reducing atmosphere of $\mathrm{CH}_{4}$, however, phase transitions minimize the oxygen permeation rate. Although Fe- or Co-based perovskites have primarily been studied, stability within a broad oxygen partial pressure range is the major problems with the application of perovskite oxides on catalytic membrane reactors, and it has been stated that $\mathrm{Ni}$ - or Fe-doped $\mathrm{LaGaO}_{3}$ exhibits a stable hole and oxide ion conductivity over a broad $p \mathrm{O}_{2}$ range, with an oxygen permeation rate of 12 cc per min on $\mathrm{La}_{0: 7} \mathrm{Sr}_{0: 3} \mathrm{Ga}_{0: 6} \mathrm{Fe}_{0: 4} \mathrm{O}_{3}$ of $0.2 \mathrm{~mm}$ thickness at $1273 \mathrm{~K}$ in $\mathrm{CH}_{4}$ partial oxidation [100]. Oxygen separation membranes and the application of catalytic membrane reactors both have significant uses, but there is a vital necessity for enhanced chemical stability.

\section{Perovskite Oxides for Solid Oxide Fuel Cells (SOFCs)}

Due to the high oxygen-reducing catalytic activity and outstanding mixed conductivity at the same time, SOFCs and air electrodes of metal-air batteries are important applications of inorganic perovskite oxides [15]. The main applications of perovskite oxides for SOFC technology are given in Table 4.

For SOFC cathodes, $\mathrm{LaCoO}_{3}$ or $\mathrm{LaMnO}_{3}$ display promise, and $\mathrm{LaGaO}_{3}$-based oxides are suitable for the electrolyte, as shown in Table 4. Additionally, some recent studies have suggested that $\mathrm{Cr}$-based perovskites can be used as anodes using perovskite components as the sole building blocks for SOFCs [101]. The growth of SOFC technology using hightemperature proton-conducting electrolytes is marginally behind that of SOFCs using oxide-ion-conducting electrolytes, mainly when compared to the development of polymer electrolyte-type fuel cells $[101,102]$. Nevertheless, the Toyota group has proven to be very effective when using $\mathrm{BaCeO}_{3}$-based electrolyte films on Pd foil for a high-power SOFC [103]. According to their findings, proton-conducting perovskite oxides could become a core driver in real SOFCs in the coming years.

\section{(i). Cathode}

The primary concern for the SOFC cathode is that oxygen molecules are electrochemically reduced to oxide. In addition to this, many criteria should be considered, including catalytic operation, thermodynamic stability, and the compatibility of mechanical and chemical properties. To fulfill these cathode specifications, perovskite oxide is the most effective material. Oxygen reduction takes place either on the surface of the electrode or at the interface of gas phase/electrolyte/electrode, which is referred as the "triple phase boundary" (TPB). The material of the electrode catalyzes oxygen molecules into atom dissociation, charging and integrating them into the electrolyte. Electrocatalytic activity is considered to be a significant parameter for cathode material. By calculating the surface reaction rate constant in the oxygen isotope exchange, catalytic activity can be hence calculated [48,104].

\section{(ii). Anode}

For SOFC anodes, a cermet (Ni- $\mathrm{Y}_{2} \mathrm{O}_{3}$-stabilized $\mathrm{ZrO}_{2}$ (BFO, YSZ)) is commonly used, which is a metal-oxide ion-conducting oxide composites. $\mathrm{Ni}$, on the other hand, is well known for being quickly deactivated by accumulation and roughening. Furthermore, Ni re-oxidation is a normal phenomenon, consequent in the cell's irreversible failure. As a result, the use of oxide as an anode has recently been suggested, with $\mathrm{La}, \mathrm{Nd}$ and other elements doped in $\mathrm{SrTiO}_{3}$ perovskite oxides, as well as other elements among the proposed oxide anodes doped in $\mathrm{SrTiO}_{3}$, etc. [105], or $\mathrm{La}_{0: 75} \mathrm{Sr}_{0: 25} \mathrm{Mn}_{0: 5} \mathrm{Cr}_{0: 5} \mathrm{O}_{3}$ (LSCrM) [106] which demonstrate promising performance as oxide anodes.

(iii). Electrolyte

For SOFC electrolytes, an oxide ion conductor is commonly used. Solid protonconducting ceramics such as $\mathrm{BaZrO}_{3}$ or $\mathrm{SrCeO}_{3}$ doped with different rare-earth cations to 
B-sites were also investigated in the case of SOFCs [103], particularly for low-temperature SOFCs. However, SOFCs using oxide-ion-conducting electrolytes are more promising in terms of their chemical stability and power density. With few exceptions, YSZ is currently the most used as the electrolyte in almost all SOFCs in commercial production processes. In addition, there is still tremendous scope for an alternative electrolyte with higher oxide ion conductivity to replace YSZ in order to increase the power density. For this reason, fluorite-structured $\mathrm{CeO}_{2}$ and $\mathrm{LaGaO}_{3}$ with perovskite structures are promising electrolytes. The first perovskite-structured pure oxide ion conductor, $\mathrm{LaGaO}_{3}$ doped with $\mathrm{Sr}$ and $\mathrm{Mg}$ (LGSM), is of particular interest [107]. LGSM oxide ion conductivity, as initially observed, is substantially higher than YSZ and is nearly equal to $\mathrm{Gd}$-doped $\mathrm{CeO}_{2}$. Partial electron conductivity is exhibited in reducing atmospheres when using $\mathrm{CeO}_{2}$, and the pure oxide ion conductivity is exhibited across a wide $\mathrm{pO}_{2}$ range, i.e., from pure oxygen to pure hydrogen, in the case of LSGM.

\section{Plasmonic Perovskite Solar Cells}

The implementation of nanoparticles with plasmonic effects is an alternative way for photon and charge carrier control, among the numerous methods for advancing solar cell technologies. Surface plasmons are able to interact through electromagnetic radiation at the interfaces or surfaces of sophisticated metal nanostructures. By engineering the shape, size, and dielectric properties of the metal nanostructures, the properties of surface plasmons can be tuned precisely. PSCs with plasmonic structures permit thinner photovoltaic absorber layers without compromising their thickness while more efficiently harvesting the solar energy $[108,109]$. Here, the effects of plasmonic nanostructures in electron transport material [110], perovskite absorbers [110,111], hole transport material [110,112] and the enhancement of effective refractive index $[113,114]$ of the medium and the solar cell performance are abridged.

\subsection{Plasmonics in Electron Transport Material}

In 2015, Yuan et al. [115] introduced a new $\mathrm{TiO}_{\mathrm{x}}-\mathrm{Au}-\mathrm{TiO}_{\mathrm{x}}$ sandwich structure to enhance the PSC performance by incorporating low-temperature-processed amorphous $\mathrm{TiO}_{\mathrm{x}}$, as shown in Figure 11a, whereas real time scanning electron microscopic image of PSC cross-section is given in Figure 11b, with the results tabulated in Table 5. Electrons injected from $\mathrm{Au}-\mathrm{NP}$ plasma decay filled the trap sites in the $\mathrm{TiO}_{x}$ conduction band. This filling of trapped sites resulted in the surface potential of $\mathrm{TiO}_{x}$ reduction $[108,116,117]$. This combination has greatly enhanced the PCE up to $16.2 \%$. In particular, improving the efficiency of the device is due to reductions in the $\mathrm{TiO}_{\mathrm{x}}$ film's surface potential and improved conductivity.
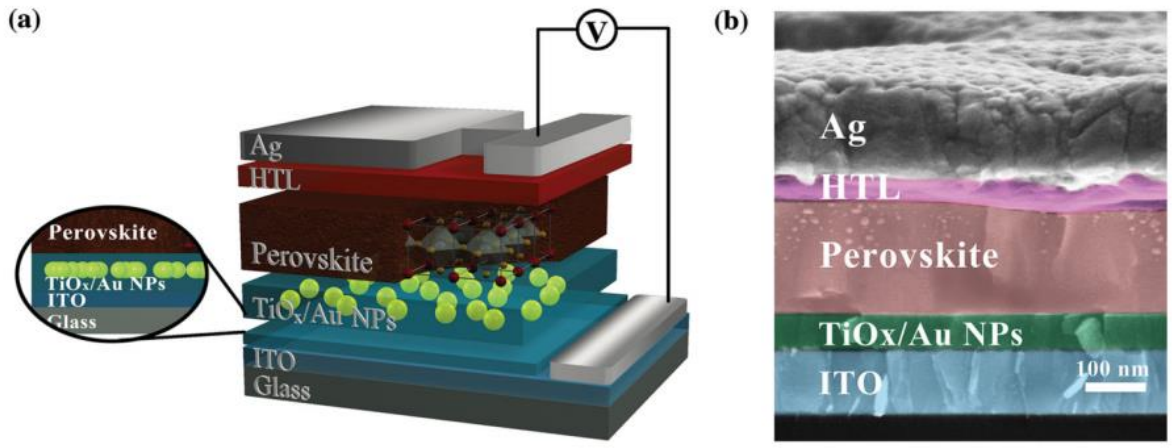

Figure 11. (a) Schematic of the (ITO/ $\left.\mathrm{TiO}_{\mathrm{x}}-\mathrm{Au}-\mathrm{NPs} / \mathrm{CH}_{3} \mathrm{NH}_{3} \mathrm{PbI}_{3-\mathrm{x}} \mathrm{Cl}_{\mathrm{x}} / \mathrm{HTL} / \mathrm{Ag}\right)$ device structure. Gold-NPs are embedded between two $\mathrm{TiO}_{x}$ layers. HTL can be either P3HT or Sprio-OMeTAD. (b) Cross-sectional SEM image of the device. Reproduced with permission from Ref. [118]. 
Table 5. Electrical output characteristics of the devices with P3HT and Spiro-OMeTAD as HTLs.

\begin{tabular}{|c|c|c|c|c|c|c|}
\hline HTL & ETL & FF & $\mathrm{J}_{\mathrm{sc}}\left[\mathrm{mA} \mathrm{cm} \mathrm{cm}^{-2}\right]$ & $\mathrm{V}_{\mathrm{oc}}[\mathrm{V}]$ & $\begin{array}{c}R_{\mathrm{s}} \\
{\left[\Omega \mathrm{cm}^{-2}\right]}\end{array}$ & PCE [\%] \\
\hline \multirow{3}{*}{ P3HT } & Control Device & $(0.63 \pm 0.02)$ & $(15.4 \pm 0.3)$ & $(0.92 \pm 0.03)$ & 15.2 & $(9.03 \pm 0.25)$ \\
\hline & $\begin{array}{c}\text { TiOx/Au-NPs } \\
\text { (Embedded) }\end{array}$ & $(0.68 \pm 0.01)$ & $(17.1 \pm 0.5)$ & $(0.95 \pm 0.02)$ & 11.2 & $(11.3 \pm 0.4)$ \\
\hline & $\begin{array}{l}\mathrm{TiOx} / \mathrm{Au}-\mathrm{NPs} \\
\text { (On top) }\end{array}$ & $(0.53 \pm 0.04)$ & $(15.0 \pm 0.6)$ & $(0.85 \pm 0.02)$ & 16.5 & $(7.05 \pm 0.37)$ \\
\hline \multirow[b]{2}{*}{ Spiro-OMeTAD } & Control Device & $(0.68 \pm 0.02)$ & $(18.6 \pm 0.3)$ & $(0.97 \pm 0.02)$ & 10.8 & $(12.3 \pm 0.6)$ \\
\hline & $\begin{array}{l}\text { TiOx/Au-NPs } \\
\text { (Embedded) }\end{array}$ & $(0.74 \pm 0.03)$ & $(19.4 \pm 0.2)$ & $(1.02 \pm 0.02)$ & 5.25 & $(14.8 \pm 0.5)$ \\
\hline
\end{tabular}

\subsection{Plasmonics in Absorber Material}

In 2013, Wei Zhang et al. [118] reported 11.4\% PCE, and the results are summarized in Figure 12d. It was attributed to plasmonic effects of incorporated Au nanoparticles as core-shell $\mathrm{Au} @ \mathrm{SiO}_{2}$ nanoparticles (NPs) in meso-superstructured organometal halide perovskite, which led to tangible enhancements in the photocurrent and PCE of solar cells (Figure 12). Enhancement in photocurrent is also attributed to reductions in exciton binding energy due to incorporated/embedded nanoparticles, rather than an enhanced light absorption.

(a)

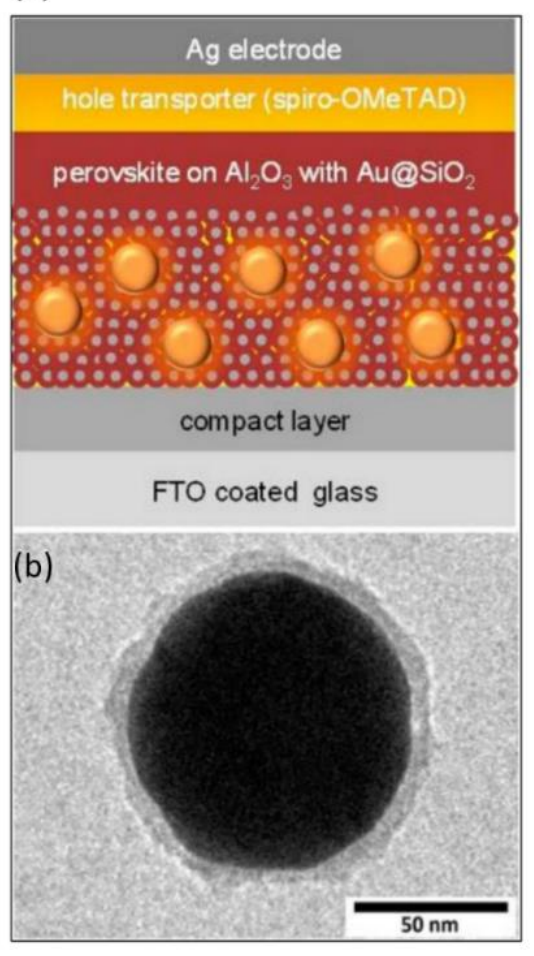

(c)

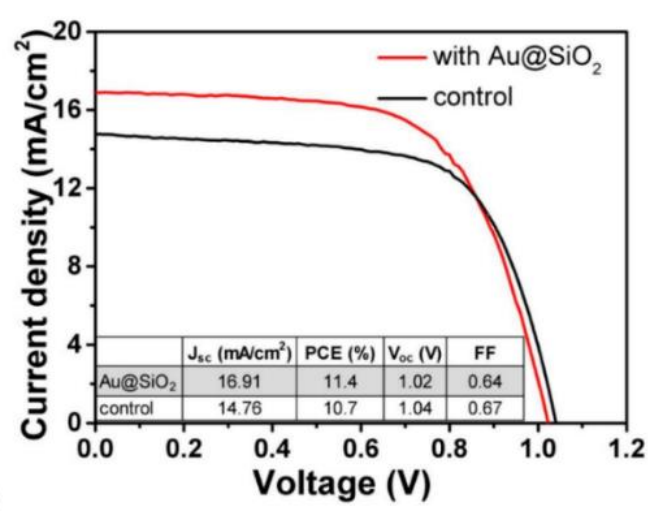

(d)

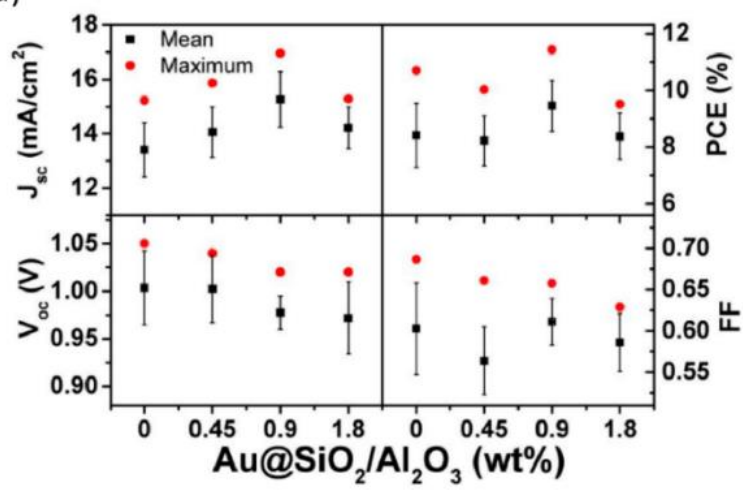

Figure 12. (a) Illustration of device structure with. (b) Typical TEM micrograph of $\mathrm{Au} @ S i O_{2} \mathrm{NPs}$. (c) J-V plots for $\mathrm{Al}_{2} \mathrm{O}_{3}$-only and ${\mathrm{Au} @ S i O_{2}}_{2}$ devices measured under STC. (d) Load dependence of $\mathrm{Au} @ \mathrm{SiO}_{2} \mathrm{NPs}$ on the device performance. Reproduced with permission from Ref. [119].

In 2016, Wu R. et al. [120] prepared planar heterojunction (PHJ) PSC with the structure of ITO/PEDOT:PSS $/ \mathrm{CH}_{3} \mathrm{NH}_{3} \mathrm{PbI}_{3} / \mathrm{PCBM} / \mathrm{Al}$ and incorporated silica-coated gold $\left(\mathrm{Au} @ \mathrm{SiO}_{2}\right)$ core-shell nanorods (NRs) to the interface between the $\mathrm{CH}_{3} \mathrm{NH}_{3} \mathrm{PbI}_{3}$ and $\mathrm{PE}-$ DOT:PSS (Figure 13). The PCE significantly increased, i.e., to $15.6 \%$, due to $\mathrm{Au} @ S i O_{2}$ 
NRs incorporation, from a previous value of $10.9 \%$. Efficiencies for different ${\mathrm{Au} @ \mathrm{SiO}_{2}}_{2}$ concentrations are given in Table 6. This enhancement was attributed to the localized surface plasmon resonance of $\mathrm{Au} @ \mathrm{SiO}_{2} \mathrm{NRs}$, rather than enhancing the incident light trapping and improved transportation and charge carrier collection.
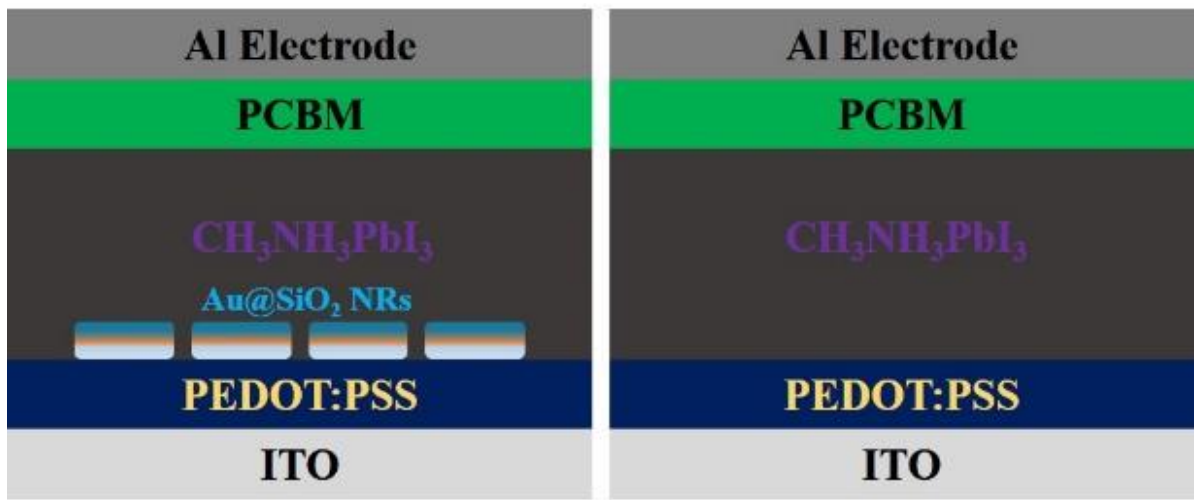

Figure 13. Glass/FTO/Au@ $\mathrm{TiO}_{2}$ nanofibers $/ \mathrm{MAPbI}_{3} /$. spiro-OMeTAD heterojunction/ $\mathrm{Au}$ (left) with and (right) without $\mathrm{Au} @ \mathrm{SiO}_{2}$ nanorods.

Table 6. With and without $\mathrm{Au} @ \mathrm{SiO}_{2}$ nanorods, PHJ-PSC devices developed JV curves showing the average performance parameters. In parentheses, the best photovoltaic parameters are given.

\begin{tabular}{|c|c|c|c|c|}
\hline $\begin{array}{c}\text { Concentration of } \mathrm{Au} @ \mathrm{SiO}_{2} \\
\text { Nanorods (pM) }\end{array}$ & $\mathrm{V}_{\mathrm{oc}}(\mathrm{V})$ & $\underset{\left(\mathrm{mA} / \mathrm{cm}^{2}\right)}{\mathrm{J}_{\mathrm{sc}}}$ & FF (\%) & PCE (\%) \\
\hline 0 & $0.99 \pm 0.05$ & $18.3 \pm 1.2$ & $59.5 \pm 4.9$ & $10.9 \pm 1.2$ \\
\hline 0.032 & $0.95 \pm 0.03$ & $18.9 \pm 1.7$ & $61.3 \pm 2.8$ & $11.2 \pm 1.3$ \\
\hline 0.047 & $1.04 \pm 0.03$ & $20.7 \pm 1.0$ & $72.0 \pm 3.4$ & $15.6 \pm 0.9$ \\
\hline 0.095 & $1.01 \pm 0.02$ & $20.3 \pm 1.0$ & $70.1 \pm 1.1$ & $14.5 \pm 0.8$ \\
\hline
\end{tabular}

In 2016, Mali et al. [121] reported a method for facilitating the generation of plasmonenhanced charge in PSC by Au-embedded $\mathrm{TiO}_{2}$ nanofiber prepared by electrospinning, i.e., glass/FTO/Au@ $\mathrm{TiO}_{2}$ nanofibers $/ \mathrm{MAPbI}_{3} /$ spiro-OMeTAD heterojunction/Au; the performance parameters are summarized in Table 7. Enhancements in the separation of the charge carrier are accredited to the perovskite and $\mathrm{Au} @ \mathrm{TiO}_{2}$ nanofibers' defect-free interface and perovskite $/ \mathrm{TiO}_{2}$ grain boundary reductions.

Table 7. $\mathrm{TiO}_{2}$ and $\mathrm{Au} @ \mathrm{TiO}_{2}$ nanofiber-based PSCs hysteresis analysis.

\begin{tabular}{|c|c|c|c|c|c|}
\hline Sample & Scan Direction & FF $\%$ & $\begin{array}{c}\text { Jsc } \\
{\left[\mathrm{mA} \mathrm{cm}^{-2}\right]}\end{array}$ & Voc [V] & $\eta[\%]$ \\
\hline \multirow{3}{*}{$\mathrm{TiO}_{2}$ nanofibers } & Forward & $59 \pm 4$ & $18.57 \pm 0.38$ & $0.898 \pm 0.02$ & $9.83 \pm 0.35$ \\
\hline & Reverse & $60 \pm 4$ & $19.52 \pm 0.38$ & $0.953 \pm 0.02$ & $11.16 \pm 0.35$ \\
\hline & Average & 59.5 & 19.045 & 0.925 & 10.48 \\
\hline \multirow{3}{*}{$\begin{array}{c}\mathrm{Au} @ \mathrm{TiO}_{2} \\
\text { nanofibers }\end{array}$} & Forward & $64 \pm 3$ & $20.16 \pm 0.38$ & $0.951 \pm 0.02$ & $12.27 \pm 0.33$ \\
\hline & Reverse & $70 \pm 2$ & $21.63 \pm 0.36$ & $0.986 \pm 0.02$ & $14.92 \pm 0.33$ \\
\hline & Average & 67 & 20.89 & 0.967 & 13.53 \\
\hline
\end{tabular}

\subsection{Plasmonics in the Hole Transport Material}

In 2015, Wang et al. [112] reported that adding Au-NPs into a conjugated poly(3hexylthiophene-2,5-diyl) (P3HT) resulted in the electrical conductivity and carrier mobility 
of the native P3HT film enhancing by approximately fourfold. This was attributed to enhanced polymer chain ordering caused by Au-NPs. An enhancement of $25 \%$ in PCE was achieved by incorporating a $20 \%$ loading of Au-NPs in P3HT film in perovskite solar cells as HTLs (Figure 14). In Table 8, solar cell efficiencies and other parameters are given, summarizing the effect each Au-NPs (\%) loading into the P3HT HTL layer.

(a)

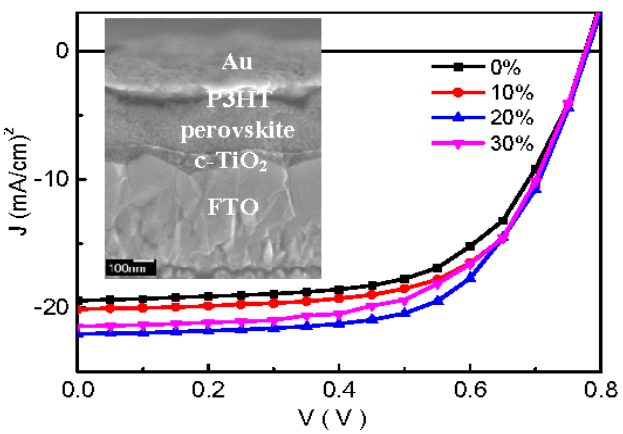

(b)

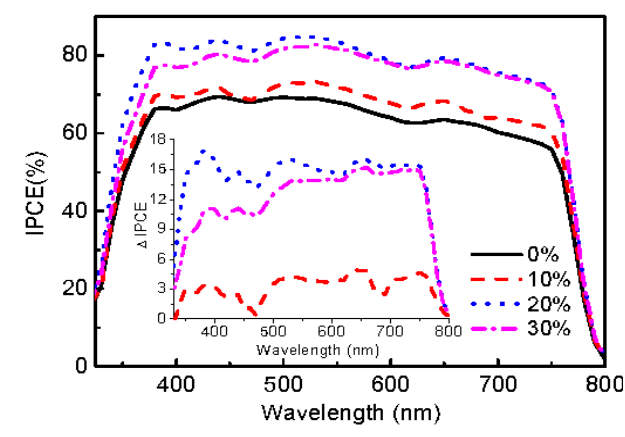

Figure 14. (a) J-V characteristics for devices with and without doping of Au-NPs in the HTLs; (b) IPCE curves for devices with and without doping of Au-NPs in the HTLs. Reproduced with permission from Ref. [115].

Table 8. With and without HTL doping with Au-NPs under STC.

\begin{tabular}{cccccc}
\hline $\mathbf{A u}(\mathbf{\%})$ & $\begin{array}{c}\mathbf{R}_{\mathbf{s}} \\
{\left[\mathbf{\mathbf { c m } ^ { - 2 } ]}\right.}\end{array}$ & $\mathbf{V}_{\mathbf{o c}}[\mathbf{V}]$ & $\mathbf{F F}$ & $\begin{array}{c}\mathbf{J}_{\mathbf{s c}} \\
{\left[\mathbf{m} \mathbf{~ c m}^{-2}\right]}\end{array}$ & $\eta[\mathbf{\%}]$ \\
\hline 0 & $12.57 \pm 2.74$ & $19.06 \pm 0.85$ & $56.11 \pm 6.04$ & $0.70 \pm 0.04$ & $7.81 \pm 0.92$ \\
\hline 10 & $11.41 \pm 2.62$ & $20.02 \pm 0.11$ & $61.03 \pm 3.04$ & $0.71 \pm 0.02$ & $8.76 \pm 0.61$ \\
\hline 20 & $10.52 \pm 2.17$ & $21.53 \pm 0.48$ & $60.72 \pm 3.86$ & $0.72 \pm 0.03$ & $9.82 \pm 0.89$ \\
\hline 30 & $11.13 \pm 2.76$ & $20.87 \pm 0.39$ & $58.81 \pm 4.22$ & $0.68 \pm 0.04$ & $8.13 \pm 0.98$ \\
\hline
\end{tabular}

\subsection{Plasmonics in Semi-Transparent PSCs}

Due to potential uses including building-integrated photovoltaics (such as in windows and cladding tiles), automotive applications, and tandem solar cells, semi-transparent solar cells attract considerable interest. The use of thin active layers and island-type structures [15], suppressing scattering by making the interfaces smoother [122], also semitransparent electrodes [119], is a general approach to semitransparent cells. In solar cells, and more generally, in optoelectronic systems, numerous examples of transparent electrodes have been used, such as thin metal films, conductive polymers [123], carbon nanotubes [124], conductive oxides [125], metal NWs [126], or graphene [102,127]. In tandem solar cells, semi-transparent PSCs can also be applied [128-130]. In 2017, Kim et al. [131] have applied silver nanocubes (Ag-NCs) to utilize electrode-coupled plasmons (ECPs). The ECP wavelength can be modulated relatively easily by adjusting the particle size and the thickness of the semiconductor layer.

In Table 9, we have summarized the plasmonics nanoparticles effects on the perovskite solar cell. The respective, investigated and proposed mechanisms due to the incorporation of different metallic nanoparticles of different sizes, morphologies and concentrations for different configurations and in different layers of the PSCs are also given. 
Table 9. Plasmonics nanoparticles applied in perovskite solar cells along with PV performances and mechanisms.

\begin{tabular}{|c|c|c|c|c|c|c|}
\hline Ref. & Structure & $\begin{array}{c}\mathrm{J}_{\mathrm{sc}} \\
\left(\mathrm{mA} / \mathrm{cm}^{2}\right)\end{array}$ & $\begin{array}{c}\mathrm{J}_{\mathrm{sc}} \\
\text { Enhancement } \\
(\%)\end{array}$ & $\begin{array}{l}\text { Efficiency } \\
(\eta \%)\end{array}$ & $\begin{array}{c}\text { Efficiency Increase } \\
(\%)\end{array}$ & Mechanism \\
\hline [132] & $\begin{array}{c}\mathrm{ITO} / \\
\text { PEDOT:PSS/MAPbI } / \mathrm{Mg} \mathrm{NPs} \\
\text { (79 nm)/PCBM/LiF/Al }\end{array}$ & 19.89 to 24.41 & 18.5 & 11.63 to 13.46 & $13.6 \%$ & $\begin{array}{l}\text { The improved Jsc and overall } \\
\text { device performance are } \\
\text { attributed to enhanced } \\
\text { absorption via LSPR and light } \\
\text { optical path length increases }\end{array}$ \\
\hline [133] & $\begin{array}{c}\text { ITO/Au NPs (120 nm):QD- } \\
\text { CsPbBr } / \\
\text { PEDOT:PSS/ } / \mathrm{MAPbI}_{3} / \mathrm{C}_{60} / \mathrm{Ag}\end{array}$ & 20.6 to 22.5 & 9 & 8.53 to 10.9 & 27.8 & $\begin{array}{l}\text { LSPR excitation and light } \\
\text { scattering }\end{array}$ \\
\hline [134] & $\begin{array}{c}\mathrm{ITO} / \\
\begin{array}{c}\text { PEDOT:PSS/MAPbI } / \\
\text { (nCBM } / \mathrm{Ag}\end{array} \\
\text { (nanocubes) } / \mathrm{BCP} / \mathrm{Ag}\end{array}$ & 19.5 to 21.4 & 9 & 11.9 to 13.3 & 10.5 & $\begin{array}{l}\text { Plasmonic Ag nanocube } \\
\text { coupling with Ag back electrode }\end{array}$ \\
\hline \multirow{2}{*}{ [135] } & $\begin{array}{c}\mathrm{ITO} / \mathrm{TiO}_{2} / \mathrm{ZrN} / \mathrm{SiO}_{2} \mathrm{NPs} \\
(75 \mathrm{~nm} \text { core } / 40 \mathrm{~nm} \\
\text { shell }) / \mathrm{MASnI}_{3} / \text { Spiro-OMeTAD } / \mathrm{Au}\end{array}$ & 27 to 40.3 & 33 & 12.9 to 20 & 35.5 & $\begin{array}{l}\text { Attributed to enhancement in } \\
\text { the plasmonic surface plasmon's } \\
\text { directivity by the dielectric shell }\end{array}$ \\
\hline & $\begin{array}{c}\text { ITO }(150 \mathrm{~nm}) / \mathrm{TiO}_{2}(40 \mathrm{~nm}) / \mathrm{ZrN} \text { NPs } \\
(100 \mathrm{~nm}) / \mathrm{MASnI}_{3}(350 \\
\mathrm{nm}) / \text { Spiro-OMeTAD }(200 \mathrm{~nm}) / \mathrm{Au}(100 \\
\mathrm{nm})\end{array}$ & 27 to 34.2 & 21 & 12.9 to 16.6 & 22.3 & $\begin{array}{c}\text { Plasmonic resonance } \\
\text { enhancement at NIR } \\
\text { wavelengths }\end{array}$ \\
\hline [118] & $\begin{array}{c}\mathrm{FTO} / \mathrm{TiO}_{2}(50 \mathrm{~nm}) / \mathrm{Al}_{2} \mathrm{O}_{3}(130 \mathrm{~nm}) \text { with } \\
\mathrm{Au}(80 \mathrm{~nm}) @ \mathrm{SiO}_{2}(8 \mathrm{~nm})+ \\
\mathrm{MAPbI}_{3} / \text { Spiro-OMeTAD } / \mathrm{Ag}\end{array}$ & 14.76 to 16.91 & 13 & 10.7 to 11.4 & 6 & $\begin{array}{c}\text { Attributed to enhanced } \\
\text { photocurrent due to enhanced } \\
\text { light absorption and plasmonic } \\
\text { localized heating }\end{array}$ \\
\hline
\end{tabular}


Table 9. Cont.

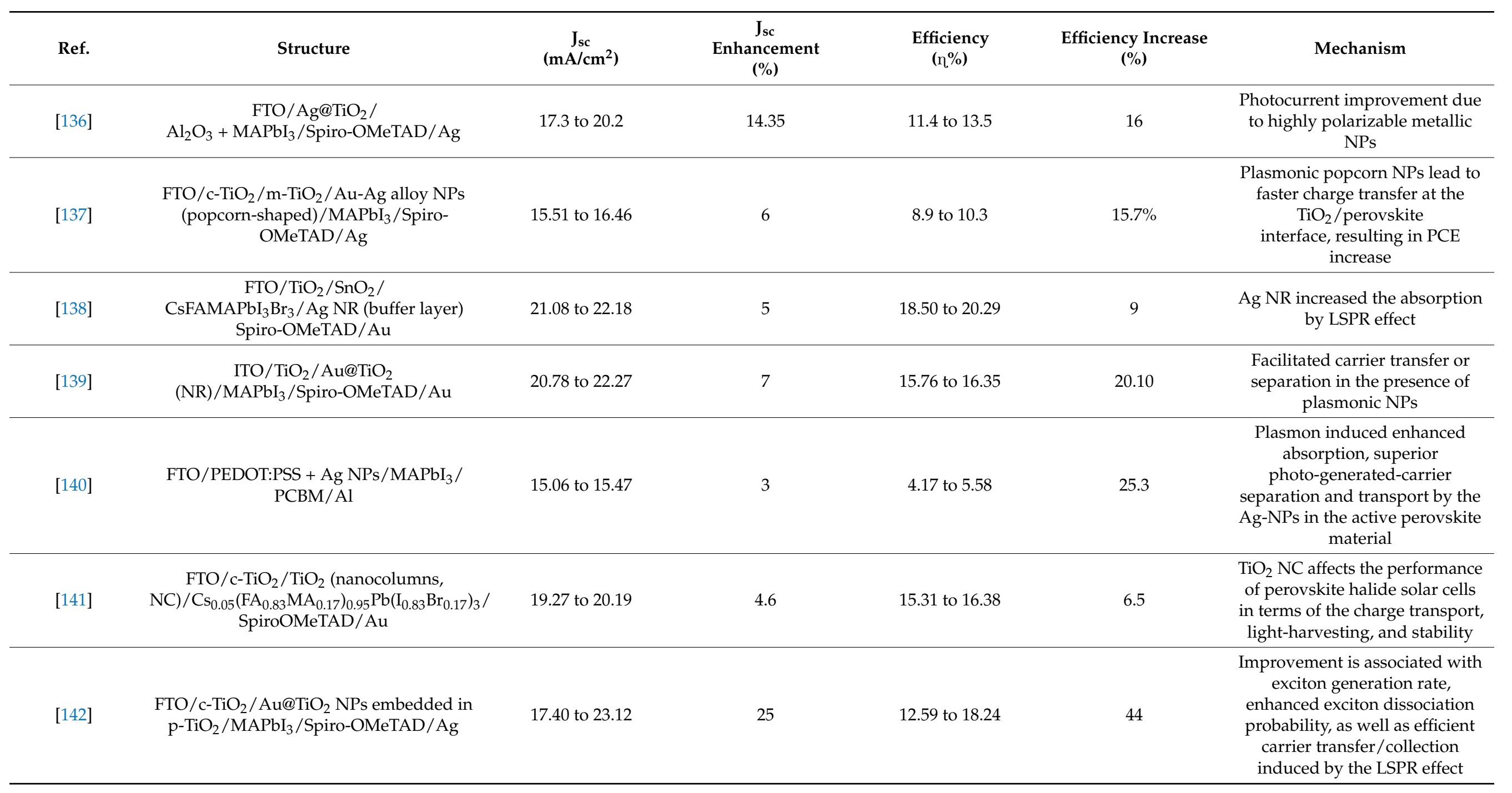


Table 9. Cont.

\begin{tabular}{|c|c|c|c|c|c|c|}
\hline Ref. & Structure & $\begin{array}{c}\mathrm{J}_{\mathrm{sc}} \\
\left(\mathrm{mA} / \mathrm{cm}^{2}\right)\end{array}$ & $\begin{array}{c}\mathrm{J}_{\mathrm{sc}} \\
\text { Enhancement } \\
(\%)\end{array}$ & $\begin{array}{l}\text { Efficiency } \\
\quad(\eta \%)\end{array}$ & $\begin{array}{l}\text { Efficiency Increase } \\
(\%)\end{array}$ & Mechanism \\
\hline [143] & $\begin{array}{c}\mathrm{ITO} / \mathrm{ZnO} / \mathrm{MAPbI}_{3} / \mathrm{Au} \\
\text { (nanostars)/Spiro-OMeTAD/Ag }\end{array}$ & 17.43 to 18.21 & 4.3 & 11.98 to 13.97 & 14 & $\begin{array}{l}\text { Absorption improved by Au } \\
\text { NSs due to SPR and } \\
\text { backscattering effects. }\end{array}$ \\
\hline [144] & $\begin{array}{c}\mathrm{FTO} / \mathrm{ZnO} / \mathrm{ZnO} \\
\mathrm{NR} / \mathrm{MAPbI}_{3} / \text { spiro-OMeTAD/Au }\end{array}$ & 18.07 to 20.56 & 12.1 & 14.51 to 16.77 & $\sim 14$ & LSPR \\
\hline [133] & $\begin{array}{c}\text { 120AuNPs: Quantum Dots (QD)-CsPbBr } 3 / \\
\text { PEDOT:PSS/MAPbI }\end{array}$ & 20.6 to 22.5 & 8.4 & 8.53 to 10.9 & $\sim 27.8$ & $\begin{array}{l}\text { LSPR excitation by resonance } \\
\text { interaction }\end{array}$ \\
\hline [145] & $\begin{array}{c}\text { ITO/ } \\
\text { PEDOT:PSS/ } \\
\mathrm{CH}_{3} \mathrm{NH}_{3} \mathrm{PbI}_{3} / \\
\mathrm{PC}_{61} \mathrm{BM} / \mathrm{Al}\end{array}$ & 16.70 to 18.15 & 8 & 10.54 to 11.74 & $\sim 10.22$ & $\begin{array}{l}\text { Sub-wavelength antenna due to } \\
\text { LSPR excitation }\end{array}$ \\
\hline
\end{tabular}




\section{Summary and Outlook}

Due to their extensive intriguing physical and chemical properties, perovskite oxides have evolved as an attractive class of materials, garnering intense research interest in condensed matter physics and a range of functional device applications. Among several practical materials, perovskite oxides have demonstrated a large variety of applications closely related to people's lives. The market for applications has been dominated by the wide use of high-performance perovskites in memory, sensors, microelectronics, piezoelectric actuators, energy harvesting and storage systems, mechanical processing, ultrasonic energy converters, and optical and other related optoelectronic devices.

The crystal structures of perovskites and associated oxides have been described throughout this study. Perovskite oxide is composed of a number of materials and components. Furthermore, in the crystals structure there are several polymorphs. Therefore, there are several functions and rich application areas dependent on the wide range of crystal structures. A brief overview of the use of perovskite oxides for photocatalytic properties and solid oxide fuel cells has been provided. Perovskite oxides are commonly used for SOFCs and oxygen permeation membranes because a high electrical conductivity and a surface activity for oxygen dissociation are obtained instantaneously. On the other hand, Taor Ti-based perovskites are highly active when applied to photocatalysts. An overview of the recent developments in plasmonic nanostructures in PSCs, including semi-transparent devices, is also presented in this study. Machine learning models trained on extensive experimental and computed databases to assess the stability of various oxide perovskites polymorphs have revealed that the chemical composition is far from being fully explored. A recent study predicted that about 500 single and double perovskites remained unreported. Considering the diverse domains of applications of oxide perovskites covered in this review, potential novel candidates predicted computationally then synthesized in the lab might help broaden the spectrum of applications to target niche technological areas.

Author Contributions: All the authors have equal contributions. All authors have read and agreed to the published version of the manuscript.

Funding: This research is funded by Qatar National Research Fund (A member of Qatar Foundation) through NPRP grant \# NPRP11S-0117-180330.

Conflicts of Interest: The authors declare no conflict of interest.

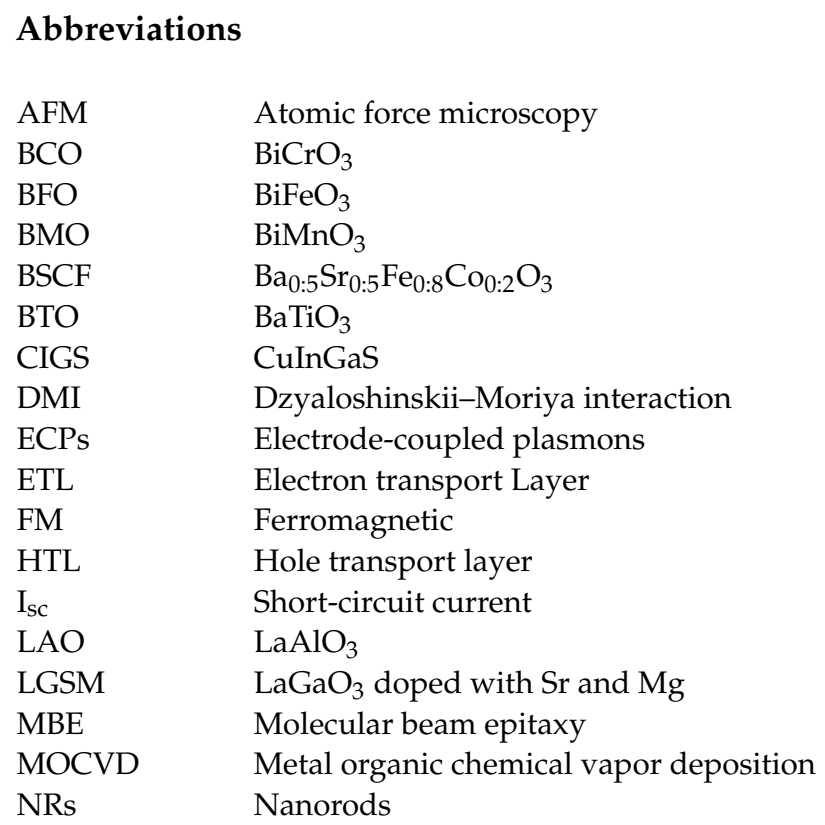




$\begin{array}{ll}\text { PCE } & \text { Power conversion efficiency } \\ \text { PFM } & \text { Piezoelectric force microscopy } \\ \text { PHJ } & \text { Planar heterojunction } \\ \text { PLD } & \text { Pulsed laser deposition } \\ \text { PSCs } & \text { Perovskite solar cells } \\ \text { PV } & \text { Photovoltaics } \\ \text { RE } & \text { Rare-earth } \\ \text { RHEED } & \text { Reflection high-energy electron diffraction } \\ \text { SG Transition } & \text { Spin glass transition } \\ \text { SOFCs } & \text { Solid oxide fuel cells } \\ \text { SOTA } & \text { State-of-the-art } \\ \text { SSO } & \text { Spiral spin order } \\ \text { STC } & \text { Standard test conditions } \\ \mathrm{T}_{\mathrm{C}} & \text { Curie temperature } \\ \mathrm{T}_{\mathrm{FE}} & \text { Ferroelectric temperature } \\ \mathrm{T}_{\mathrm{FM}} & \text { Ferromagnetic temperature } \\ \mathrm{TMO} & \text { Transition metal oxide } \\ \text { TWC } & \text { Three-way catalyst } \\ \mathrm{V}_{\mathrm{OC}} & \text { Open-circuit voltage } \\ \text { YMO } & \text { YMnO } \\ \text { YSZ } & \mathrm{Y}_{0: 16} \mathrm{Zr}_{0: 84} \mathrm{O}_{2}\end{array}$

\section{References}

1. $\mathrm{Wu}, \mathrm{Y}$.; Li, J.; Xu, J.; Du, Y.; Huang, L.; Ni, J.; Cai, H.; Zhang, J. Organic-inorganic hybrid CH3NH3PbI3 perovskite materials as channels in thin-film field-effect transistors. RSC Adv. 2016, 6, 16243-16249. [CrossRef]

2. Stranks, S.D.; Snaith, H. Metal-halide perovskites for photovoltaic and light-emitting devices. Nat. Nanotechnol. 2015, 10, 391-402. [CrossRef]

3. Waser, R.; Dittmann, R.; Staikov, G.; Szot, K. Redox-Based Resistive Switching Memories-Nanoionic Mechanisms, Prospects, and Challenges. Adv. Mater. 2009, 21, 2632-2663. [CrossRef]

4. Suntivich, J.; May, K.J.; Gasteiger, H.A.; Goodenough, J.B.; Shao-Horn, Y. A Perovskite Oxide Optimized for Oxygen Evolution Catalysis from Molecular Orbital Principles. Science 2011, 334, 1383-1385. [CrossRef]

5. $\quad$ Reyren, N.; Thiel, S.; Caviglia, A.D.; Kourkoutis, L.F.; Hammerl, G.; Richter, C.; Schneider, C.W.; Kopp, T.; Ruetschi, A.-S.; Jaccard, D.; et al. Superconducting Interfaces Between Insulating Oxides. Science 2007, 317, 1196-1199. [CrossRef]

6. Peña, M.A.; Fierro, J.L.G. Chemical Structures and Performance of Perovskite Oxides. Chem. Rev. 2001, 101, 1981-2018. [CrossRef]

7. Kobayashi, K.-I.; Kimura, T.; Sawada, H.; Terakura, K.; Tokura, Y. Room-temperature magnetoresistance in an oxide material with an ordered double-perovskite structure. Nature 1998, 395, 677-680. [CrossRef]

8. Huang, Y.-H.; Dass, R.I.; Xing, Z.-L.; Goodenough, J.B. Double Perovskites as Anode Materials for Solid-Oxide Fuel Cells. Science 2006, 312, 254-257. [CrossRef]

9. Chroneos, A.; Vovk, R.; Goulatis, I.; Goulatis, L. Oxygen transport in perovskite and related oxides: A brief review. J. Alloys Compd. 2010, 494, 190-195. [CrossRef]

10. Jin, S.; Tiefel, T.H.; McCormack, M.; Fastnacht, R.A.; Ramesh, R.; Chen, L.H. Thousandfold Change in Resistivity in Magnetoresistive La-Ca-Mn-O Films. Science 1994, 264, 413-415. [CrossRef]

11. Nechache, R.; Harnagea, C.; Li, S.; Cardenas, L.; Huang, W.; Chakrabartty, J.; Rosei, F. Bandgap tuning of multiferroic oxide solar cells. Nat. Photonics 2014, 9, 61-67. [CrossRef]

12. Sun, Q.; Wang, J.; Yin, W.; Yan, Y. Bandgap Engineering of Stable Lead-Free Oxide Double Perovskites for Photovoltaics. Adv. Mater. 2018, 30, e1705901. [CrossRef]

13. Kim, H.-S.; Lee, C.-R.; Im, J.-H.; Lee, K.-B.; Moehl, T.; Marchioro, A.; Moon, S.-J.; Humphry-Baker, R.; Yum, J.-H.; Moser, J.-E.; et al Lead Iodide Perovskite Sensitized All-Solid-State Submicron Thin Film Mesoscopic Solar Cell with Efficiency Exceeding 9\%. Sci. Rep. 2012, 2, 591. [CrossRef]

14. Green, M.A.; Ho-Baillie, A.; Snaith, H. The emergence of perovskite solar cells. Nat. Photonics 2014, 8, 506-514. [CrossRef]

15. Eperon, G.E.; Leijtens, T.; Bush, K.A.; Prasanna, R.; Green, T.; Wang, J.T.-W.; McMeekin, D.P.; Volonakis, G.; Milot, R.L.; May, R.; et al. Perovskite-perovskite tandem photovoltaics with optimized band gaps. Science 2016, 354, 861-865. [CrossRef]

16. NREL. Best Research-Cell Efficiencies 1975-2010. 2013. Available online: https://www.nrel.gov/pv/cell-efficiency.html (accessed on 11 August 2021).

17. Geller, S.; Jeffries, J.B.; Curlander, P.J. The crystal structure of a new high-temperature modification of YGaO3. Acta Crystallogr. Sect. B Struct. Crystallogr. Cryst. Chem. 1975, 31, 2770-2774. [CrossRef]

18. Liebermann, R.C.; Jones, L.E.; Ringwood, A. Elasticity of aluminate, titanate, stannate and germanate compounds with the perovskite structure. Phys. Earth Planet. Inter. 1977, 14, 165-178. [CrossRef]

19. Schaak, R.E.; Mallouk, T. Perovskites by Design: A Toolbox of Solid-State Reactions. Chem. Mater. 2002, 14, 1455-1471. [CrossRef] 
20. Chern, M.Y.; Vennos, D.; Disalvo, F. Synthesis, structure, and properties of anti-perovskite nitrides $\mathrm{Ca}_{3} \mathrm{MN}, \mathrm{M}=\mathrm{P}, \mathrm{As}, \mathrm{Sb}, \mathrm{Bi}, \mathrm{Ge}$, $\mathrm{Sn}$, and Pb. J. Solid State Chem. 1992, 96, 415-425. [CrossRef]

21. Zhao, Y.; Daemen, L.L. Superionic Conductivity in Lithium-Rich Anti-Perovskites. J. Am. Chem. Soc. 2012, 134, 15042-15047. [CrossRef]

22. Stølen, S.; Bakken, E.; Mohn, C.E. Oxygen-deficient perovskites: Linking structure, energetics and ion transport. Phys. Chem. Chem. Phys. 2005, 8, 429-447. [CrossRef] [PubMed]

23. Aleksandrov, K.S. Structural phase transitions in layered perovskitelike crystals. Crystallogr. Rep. 1995, 40, 251-272.

24. Ruddlesden, S.N.; Popper, P. The compound Sr3Ti2O7and its structure. Acta Crystallogr. 1958, 11, 54-55. [CrossRef]

25. Ruddlesden, S.N.; Popper, P. New compounds of the K2NIF4type. Acta Crystallogr. 1957, 10, 538-539. [CrossRef]

26. Aurivillius, B. Mixed bismuth oxides with layer lattices. 2. Structure of $\mathrm{Bi}_{4} \mathrm{Ti}_{3} \mathrm{O}_{12}$. Ark. Kemi. 1950, 1, 499-512.

27. Aurivillius, B. Mixed bismuth oxides with layer lattices. 1. The structure type of $\mathrm{CaNb}_{2} \mathrm{Bi}_{2} \mathrm{O}_{9}$. J. Ark. Kemi. 1950, 1, 463-480.

28. Benedek, N.A.; Rondinelli, J.M.; Djani, H.; Ghosez, P.; Lightfoot, P. Understanding ferroelectricity in layered perovskites: New ideas and insights from theory and experiments. Dalton Trans. 2015, 44, 10543-10558. [CrossRef] [PubMed]

29. Talapatra, A.; Uberuaga, B.P.; Stanek, C.R.; Pilania, G. A Machine Learning Approach for the Prediction of Formability and Thermodynamic Stability of Single and Double Perovskite Oxides. Chem. Mater. 2021, 33, 845-858. [CrossRef]

30. He, Z.; Gu, J.H.; Sha, W.E.I.; Chen, R.S. Efficient volumetric method of moments for modeling plasmonic thin-film solar cells with periodic structures. Opt. Express 2018, 26, 25037-25046. [CrossRef] [PubMed]

31. Ali, A.; Park, H.; Mall, R.; Aïssa, B.; Sanvito, S.; Bensmail, H.; Belaidi, A.; El-Mellouhi, F. Machine Learning Accelerated Recovery of the Cubic Structure in Mixed-Cation Perovskite Thin Films. Chem. Mater. 2020, 32, 2998-3006. [CrossRef]

32. Mitchell, R. Perovskite Modern and Ancient; Almaz Press: Thunder Bay, ON, USA, 2002.

33. Bednorz, J.G. Possible highTc superconductivity in the Ba-La-Cu-O system. Z. Für Phys. B Condens. Matter. 1986, 64, 189-193. [CrossRef]

34. Hor, P.H.; Meng, R.L.; Wang, Y.Q.; Gao, L.; Huang, Z.J.; Bechtold, J.; Forster, K.; Chu, C.W. Superconductivity above 90 K in the square-planar compound system $\mathrm{ABa} / \mathrm{sub} 2 / \mathrm{Cu} / \mathrm{sub} 3 / \mathrm{O} / \mathrm{sub} 6+/ /$ sub x/with A=Y, La, Nd, Sm, Eu, Gd, Ho, Er and Lu. Phys. Rev. Lett. 1987, 58, 1891-1894. [CrossRef]

35. Gao, L.; Xue, Y.Y.; Chen, F.; Xiong, Q.; Meng, R.L.; Ramirez, D.; Chu, C.W.; Eggert, J.H.; Mao, H.K. Superconductivity up to 164 K in $\mathrm{HgBa}_{2} \mathrm{Ca}_{\mathrm{m}-1} \mathrm{Cu}_{\mathrm{m}} \mathrm{O}_{2 \mathrm{~m}+2+\delta}(\mathrm{m}=1,2$, and 3$)$ under quasihydrostatic pressures. Phys. Rev. B 1994, 50, 4260-4263. [CrossRef] [PubMed]

36. Mizusaki, J.; Yoshihiro, M.; Yamauchi, S.; Fueki, K. Nonstoichiometry and defect structure of the perovskite-type oxides La1-xSrxFeO3- ${ }^{\circ}$. J. Solid State Chem. 1985, 58, 257-266. [CrossRef]

37. Mizusaki, J.; Yasuda, I.; Shimoyama, J.; Yamauchi, S.; Fueki, K. Electrical Conductivity, Defect Equilibrium and Oxygen Vacancy Diffusion Coefficient of $\mathrm{La}_{1-x} \mathrm{Ca}_{x} \mathrm{AlO}_{3-\delta}$ Single Crystals. J. Electrochem. Soc. 1993, 140, 467-471. [CrossRef]

38. Whang, S.-J.; Lee, S.; Chi, D.-Z.; Yang, W.-F.; Cho, B.-J.; Liew, Y.F.; Kwong, D.-L. B-doping of vapour-liquid-solid grown Au-catalysed and Al-catalysed Si nanowires: Effects of B2H6 gas during Si nanowire growth and B-doping by a post-synthesis in situ plasma. Nanotechnology 2017, 18, 275302. [CrossRef]

39. Teraoka, Y.; Harada, T.; Kagawa, S. Reaction mechanism of direct decomposition of nitric oxide over Co- and Mn-based perovskite-type oxides. J. Chem. Soc. Faraday Trans. 1998, 94, 1887-1891. [CrossRef]

40. Yasuda, H.; Nitadori, T.; Mizuno, N.; Misono, M. Catalytic Decomposition of Nitrogen Monoxide over Valency-Controlled $\mathrm{La}_{2} \mathrm{CuO}_{4}$-Based Mixed Oxides. Bull. Chem. Soc. Jpn. 1993, 66, 3492-3502. [CrossRef]

41. Iwakuni, H.; Shinmyou, Y.; Yano, H.; Matsumoto, H.; Ishihara, T. Direct decomposition of $\mathrm{NO}_{\text {into }} \mathrm{N}_{2}$ and $\mathrm{O}_{2}$ on $\mathrm{BaMnO}_{3}$-based perovskite oxides. Appl. Catal. B Environ. 2007, 74, 299-306. [CrossRef]

42. Nishihata, Y.; Mizuki, J.I.; Akao, T.; Tanaka, H.; Uenishi, M.; Kimura, M.; Okamoto, T.; Hamada, N. Self-regeneration of a Pd-perovskite catalyst for automotive emissions control. Nature 2002, 418, 164-167. [CrossRef]

43. Maeda, K. Photocatalytic water splitting using semiconductor particles: History and recent developments. J. Photochem. Photobiol. C Photochem. Rev. 2011, 12, 237-268. [CrossRef]

44. Cheong, S.-W.; Mostovoy, M.V. Multiferroics: A magnetic twist for ferroelectricity. Nat. Mater. 2007, 6, 13-20. [CrossRef] [PubMed]

45. Wang, K.; Liu, J.-M.; Ren, Z.F. Multiferroicity: The coupling between magnetic and polarization orders. Adv. Phys. 2009, 58, 321-448. [CrossRef]

46. Spaldin, N.A. MATERIALS SCIENCE: The Renaissance of Magnetoelectric Multiferroics. Science 2005, 309, 391-392. [CrossRef]

47. Ramesh, R.; Spaldin, N. Multiferroics: Progress and prospects in thin films. Nat. Mater. 2007, 6, 21-29. [CrossRef]

48. Choi, K.H.; Ali, A.; Rahman, A.; Mohammad, N.M.; Rahman, K.; Khan, A.; Khan, S.; Kim, D.S. Electrode configuration effects on the electrification and voltage variation in an electrostatic inkjet printing head. J. Micromech. Microeng. 2010, $20,075033$. [CrossRef]

49. Ali, A.; Jo, J.; Yang, Y.J.; Choi, K.H. Direct fabrication of graphene/zinc oxide composite film and its characterizations. Appl. Phys. A 2013, 114, 323-330. [CrossRef]

50. Bucci, J.D.; Robertson, B.K.; James, W.J. The precision determination of the lattice parameters and the coefficients of thermal expansion of $\mathrm{BiFeO}_{3}$. J. Appl. Crystallogr. 1972, 5, 187-191. [CrossRef]

51. Teague, J.R.; Gerson, R.; James, W. Dielectric hysteresis in single crystal BiFeO 3 . Solid State Commun. 1970, 8, 1073-1074. [CrossRef] 
52. Michel, C.; Moreau, J.-M.; Achenbach, G.D.; Gerson, R.; James, W. The atomic structure of BiFeO 3 . Solid State Commun. 1969, 7, 701-704. [CrossRef]

53. Wang, J.; Neaton, J.B.; Zheng, H.; Nagarajan, V.; Ogale, S.B.; Liu, B.; Viehland, D.; Vaithyanathan, V.; Schlom, D.G.; Waghmare, U.V.; et al. Epitaxial $\mathrm{BiFeO}_{3}$ Multiferroic Thin Film Heterostructures. Science 2003, 299, 1719-1722. [CrossRef]

54. Lee, Y.-H.; Wu, J.-M.; Lai, C.-H. Influence of La doping in multiferroic properties of $\mathrm{BiFeO}_{3}$ thin films. Appl. Phys. Lett. 2006, 88, 042903. [CrossRef]

55. Schwarzkopf, J.; Fornari, R. Epitaxial growth of ferroelectric oxide films. Prog. Cryst. Growth Charact. Mater. 2006, 52, 159-212. [CrossRef]

56. Baettig, P.; Spaldin, N. Ab initio prediction of a multiferroic with large polarization and magnetization. Appl. Phys. Lett. 2004, 86, 012505. [CrossRef]

57. Prellier, W.; Singh, M.P.; Murugavel, P. The single-phase multiferroic oxides: From bulk to thin film. J. Physics: Condens. Matter 2005, 17, R803-R832. [CrossRef]

58. Van Aken, B.; Palstra, T.T.; Filippetti, A.; Spaldin, N. The origin of ferroelectricity in magnetoelectric $\mathrm{YMnO}_{3}$. Nat. Mater. 2004, 3, 164-170. [CrossRef] [PubMed]

59. Zavaliche, F.; Yang, S.Y.; Zhao, T.; Chu, Y.-H.; Cruz, M.P.; Eom, C.B.; Ramesh, R. Multiferroic BiFeO ${ }_{3}$ films: Domain structure and polarization dynamics. Phase Transit. 2006, 79, 991-1017. [CrossRef]

60. Catalan, G.; Scott, J.F. Physics and Applications of Bismuth Ferrite. Adv. Mater. 2009, 21, 2463-2485. [CrossRef]

61. Atou, T.; Chiba, H.; Ohoyama, K.; Yamaguchi, Y.; Syono, Y. Structure Determination of Ferromagnetic Perovskite BiMnO 3 . J. Solid State Chem. 1999, 145, 639-642. [CrossRef]

62. Gajek, M.; Bibes, M.; Barthélémy, A.; Bouzehouane, K.; Fusil, S.; Varela, M.; Fontcuberta, J.; Fert, A. Spin filtering through ferromagneticBiMnO 3 tunnel barriers. Phys. Rev. B 2005, 72, 020406. [CrossRef]

63. Eerenstein, W.; Morrison, F.D.; Scott, J.F.; Mathur, N.D. Growth of highly resistive BiMnO 3 films. Appl. Phys. Lett. 2005, 87, 101906. [CrossRef]

64. Zurbuchen, M.A.; Wu, T.; Saha, S.; Mitchell, J.; Streiffer, S.K. Multiferroic composite ferroelectric-ferromagnetic films. Appl. Phys. Lett. 2005, 87, 232908. [CrossRef]

65. Hill, N.A.; Bättig, P.; Daul, C. First Principles Search for Multiferroism in BiCrO3. J. Phys. Chem. B 2002, 106, 3383-3388. [CrossRef]

66. Baettig, P.; Ederer, C.; Spaldin, N. First principles study of the multiferroics $\mathrm{BiFeO}_{3}, \mathrm{Bi}_{2} \mathrm{FeCrO}_{6}$ and $\mathrm{BiCrO}_{3}$ : Structure, polarization, and magnetic ordering temperature. Phys. Rev. B 2005, 72, 214105. [CrossRef]

67. Murakami, M.; Fujino, S.; Lim, S.-H.; Long, C.J.; Salamanca-Riba, L.G.; Wuttig, M.; Takeuchi, I.; Nagarajan, V.; Varatharajan, A. Fabrication of multiferroic epitaxial $\mathrm{BiCrO}_{3}$ thin films. Appl. Phys. Lett. 2006, 88, 152902. [CrossRef]

68. Kim, D.H.; Lee, H.N.; Varela, M.; Christen, H. Antiferroelectricity in multiferroic $\mathrm{BiCrO}_{3}$ epitaxial films. Appl. Phys. Lett. 2006, 89, 162904. [CrossRef]

69. Alonso, J.A.; Martínez-Lope, A.M.J.; Casais, M.T.; Fernández-Díaz, M.T. Evolution of the Jahn-Teller Distortion of MnO 6 Octahedra in $\mathrm{RMnO}_{3}$ Perovskites $(\mathrm{R}=\mathrm{Pr}, \mathrm{Nd}, \mathrm{Dy}, \mathrm{Tb}, \mathrm{Ho}, \mathrm{Er}, \mathrm{Y})$ : A Neutron Diffraction Study. Inorg. Chem. 2000, 39, 917-923. [CrossRef] [PubMed]

70. Cheng, C.-J.; Lu, C.; Chen, Z.; You, L.; Chen, L.; Wang, J.; Wu, T. Thickness-dependent magnetism and spin-glass behaviors in compressively strained $\mathrm{BiFeO}_{3}$ thin films. Appl. Phys. Lett. 2011, 98, 242502. [CrossRef]

71. Yang, C.-H.; Koo, T.Y.; Lee, S.-H.; Song, C.; Lee, K.-B.; Jeong, Y.H. Orbital ordering and enhanced magnetic frustration of strained $\mathrm{BiMnO}_{3}$ thin films. EPL Europhys. Lett. 2006, 74, 348-354. [CrossRef]

72. Bhatnagar, A.; Kim, Y.H.; Hesse, D.; Alexe, M. Persistent Photoconductivity in Strained Epitaxial BiFeO 3 Thin Films. Nano Lett. 2014, 14, 5224-5228. [CrossRef]

73. Kimura, T.; Goto, T.; Shintani, H.; Ishizaka, K.; Arima, T.-H.; Tokura, Y. Magnetic control of ferroelectric polarization. Nature 2003, 426, 55-58. [CrossRef] [PubMed]

74. Tokura, Y.; Seki, S. Multiferroics with Spiral Spin Orders. Adv. Mater. 2010, 22, 1554-1565. [CrossRef] [PubMed]

75. Kimura, T. Spiral Magnets as Magnetoelectrics. Annu. Rev. Mater. Res. 2007, 37, 387-413. [CrossRef]

76. Seki, S.; Onose, Y.; Tokura, Y. Spin-Driven Ferroelectricity in Triangular Lattice Antiferromagnets $\mathrm{ACrO} 2(\mathrm{~A}=\mathrm{Cu}, \mathrm{Ag}, \mathrm{Li}$, or $\mathrm{Na})$. Phys. Rev. Lett. 2008, 101, 067204. [CrossRef] [PubMed]

77. Luo, S.; Wang, K.F.; Li, S.Z.; Dong, X.W.; Yan, Z.B.; Cai, H.L.; Liu, J.-M. Enhanced ferromagnetism and ferroelectricity in multiferroic $\mathrm{CuCr}_{1-\mathrm{x}} \mathrm{Ni}_{\mathrm{x}} \mathrm{O}_{2}$. Appl. Phys. Lett. 2009, 94, 172504. [CrossRef]

78. Kimura, K.; Nakamura, H.; Kimura, S.; Hagiwara, M.; Kimura, T. Tuning Ferroelectric Polarization Reversal by Electric and Magnetic Fields in $\mathrm{CuCrO}_{2}$. Phys. Rev. Lett. 2009, 103, 107201. [CrossRef]

79. Hiraga, H.; Makino, T.; Fukumura, T.; Weng, H.; Kawasaki, M. Electronic structure of the delafossite-type $\mathrm{CuMO} 2(\mathrm{M}=\mathrm{Sc}, \mathrm{Cr}, \mathrm{Mn}$, Fe, and Co): Optical absorption measurements and first-principles calculations. Phys. Rev. B 2011, 84, 041411. [CrossRef]

80. Hiraga, H.; Makino, T.; Fukumura, T.; Ohtomo, A.; Kawasaki, M. Excitonic characteristics in direct wide-band-gap CuScO 2 epitaxial thin films. Appl. Phys. Lett. 2009, 95, 211908. [CrossRef]

81. Sergienko, I.A.; Dagotto, E. Role of the Dzyaloshinskii-Moriya interaction in multiferroic perovskites. Phys. Rev. B 2006, 73, 094434. [CrossRef]

82. Holcomb, M.B.; Martin, L.W.; Scholl, A.; He, Q.; Yu, P.; Yang, C.-H.; Yang, S.Y.; Glans, P.-A.; Valvidares, M.; Huijben, M.; et al. Probing the evolution of antiferromagnetism in multiferroics. Phys. Rev. B 2010, 81, 134406. [CrossRef] 
83. Singh, M.; Prellier, W.; Katiyar, R.S.; Scott, J.F. Spin-glass transition in single-crystal BiFeO. Phys. Rev. B 2008, 77, 144403. [CrossRef]

84. Sicot, L. Improvement of the photovoltaic properties of polythiophene-based cells. Sol. Energy Mater. Sol. Cells 2000, 63, 49-60. [CrossRef]

85. Seidel, J.; Fu, D.; Yang, S.-Y.; Llado, E.A.; Wu, J.; Ramesh, R.; Ager, J. Efficient Photovoltaic Current Generation at Ferroelectric Domain Walls. Phys. Rev. Lett. 2011, 107, 126805. [CrossRef]

86. Yang, S.Y.; Seidel, J.; Byrnes, S.; Shafer, P.; Yang, C.-H.; Rossell, M.D.; Yu, P.; Chu, Y.-H.; Scott, J.F.; Ager, J.; et al. Above-bandgap voltages from ferroelectric photovoltaic devices. Nat. Nanotechnol. 2010, 5, 143-147. [CrossRef] [PubMed]

87. Choi, T.; Lee, S.; Choi, Y.J.; Kiryukhin, V.; Cheong, S.-W. Switchable Ferroelectric Diode and Photovoltaic Effect in BiFeO 3 . Science 2009, 324, 63-66. [CrossRef] [PubMed]

88. Yao, K.; Gan, B.K.; Chen, M.; Shannigrahi, S. Large photo-induced voltage in a ferroelectric thin film with in-plane polarization. Appl. Phys. Lett. 2005, 87, 212906. [CrossRef]

89. Qin, M.; Yao, K.; Liang, Y.C. High efficient photovoltaics in nanoscaled ferroelectric thin films. Appl. Phys. Lett. 2008, 93, 122904. [CrossRef]

90. Qin, M.; Yao, K.; Liang, Y.C. Photovoltaic mechanisms in ferroelectric thin films with the effects of the electrodes and interfaces. Appl. Phys. Lett. 2009, 95, 022912. [CrossRef]

91. Bhatnagar, A.; Chaudhuri, A.R.; Kim, Y.H.; Hesse, D.; Alexe, M. Role of domain walls in the abnormal photovoltaic effect in BiFeO3. Nat. Commun. 2013, 4, 2835. [CrossRef]

92. Yuan, G.-L.; Wang, J. Evidences for the depletion region induced by the polarization of ferroelectric semiconductors. Appl. Phys. Lett. 2009, 95, 252904. [CrossRef]

93. Yi, H.T.; Choi, T.; Choi, S.G.; Oh, Y.S.; Cheong, S.-W. Mechanism of the Switchable Photovoltaic Effect in Ferroelectric BiFeO3. Adv. Mater. 2011, 23, 3403-3407. [CrossRef]

94. Guo, R.; You, L.; Zhou, Y.; Lim, Z.S.; Zou, X.; Chen, L.; Ramesh, R.; Wang, J. Non-volatile memory based on the ferroelectric photovoltaic effect. Nat. Commun. 2013, 4, 1990. [CrossRef]

95. Kundys, B.; Viret, M.; Colson, D.; Kundys, D. Light-induced size changes in $\mathrm{BiFeO}_{3}$ crystals. Nat. Mater. 2010, 9, 803-805. [CrossRef]

96. Fergus, J. Lanthanum chromite-based materials for solid oxide fuel cell interconnects. Solid State Ionics 2004, 171, 1-15. [CrossRef]

97. Kilner, J. Fast oxygen transport in acceptor doped oxides. Solid State Ion. 2000, 129, 13-23. [CrossRef]

98. Yashima, M.; Yamada, H.; Nuansaeng, S.; Ishihara, T. Role of $\mathrm{Ga}^{3+}$ and $\mathrm{Cu}^{2+}$ in the High Interstitial Oxide-Ion Diffusivity of $\mathrm{Pr}_{2} \mathrm{NiO}_{4}$-Based Oxides: Design Concept of Interstitial Ion Conductors through the Higher-Valence d10 Dopant and Jahn-Teller Effect. Chem. Mater. 2012, 24, 4100-4113. [CrossRef]

99. Ma, B.; Balachandran, U.; Park, J.; Segre, C.U. Electrical Transport Properties and Defect Structure of SrFeCo ${ }_{0.5} \mathrm{O}_{x}$. J. Electrochem. Soc. 1996, 143, 1736-1744. [CrossRef]

100. Ishihara, T. Fe doped $\mathrm{LaGaO} 3$ perovskite oxide as an oxygen separating membrane for $\mathrm{CH} 4$ partial oxidation. Solid State Ionics 2002, 152-153, 709-714. [CrossRef]

101. Perovskite Oxide for Solid Oxide Fuel Cells; Springer: Basel, Switzerland, 2009. [CrossRef]

102. Choi, K.H.; Ali, A.; Kim, H.C.; Hyun, M.T. Fabrication of dielectric poly (4-vinylphenol) thin films by using the electrohydrodynamic atomization technique. J. Korean Phys. Soc. 2013, 62, 269-274. [CrossRef]

103. Tao, S.W.; Irvine, J.T.S.; Kilner, J.A. An Efficient Solid Oxide Fuel Cell Based upon Single-Phase Perovskites. Adv. Mater. 2005, 17, 1734-1737. [CrossRef]

104. Ito, N.; Iijima, M.; Kimura, K.; Iguchi, S. New intermediate temperature fuel cell with ultra-thin proton conductor electrolyte. J. Power Sources 2005, 152, 200-203. [CrossRef]

105. Druce, J.; Tellez, H.; Burriel, M.; Sharp, M.D.; Fawcett, L.J.; Cook, S.N.; McPhail, D.S.; Ishihara, T.; Brongersma, H.H.; Kilner, J.A. Surface termination and subsurface restructuring of perovskite-based solid oxide electrode materials. Energy Environ. Sci. 2014, 7, 3593-3599. [CrossRef]

106. Irvine, J.T.S.; Slater, P.; Wright, P.A. Synthesis and electrical characterisation of the perovskite niobate-titanates, $\mathrm{Sr}_{1-\mathrm{x} / 2} \mathrm{Ti}_{1-\mathrm{x}} \mathrm{Nbx}$ $\mathrm{O}_{3-\delta}$. Ionics 1996, 2, 213-216. [CrossRef]

107. Iwahara, H.; Esaka, T.; Uchida, H.; Maeda, N. Proton conduction in sintered oxides and its application to steam electrolysis for hydrogen production. Solid State Ion. 1981, 3-4, 359-363. [CrossRef]

108. Atwater, H.A.; Polman, A. Plasmonics for improved photovoltaic devices. Nat. Mater. 2010, 9, 205-213. [CrossRef]

109. Tooghi, A.; Fathi, D.; Eskandari, M. High-performance perovskite solar cell using photonic-plasmonic nanostructure. Sci. Rep. 2020, 10, 11248. [CrossRef]

110. Ameen, S.; Rub, M.A.; Kosa, S.A.; Alamry, K.A.; Akhtar, M.S.; Shin, H.-S.; Seo, H.-K.; Asiri, A.M.; Nazeeruddin, M.K. Perovskite Solar Cells: Influence of Hole Transporting Materials on Power Conversion Efficiency. ChemSusChem 2015, 9, 10-27. [CrossRef] [PubMed]

111. Zhou, Z.; Pang, S.; Liu, Z.; Xu, H.; Cui, G. Interface engineering for high-performance perovskite hybrid solar cells. J. Mater. Chem. A 2015, 3, 19205-19217. [CrossRef]

112. Wang, J.-Y.; Hsu, F.-C.; Huang, J.-Y.; Wang, L.; Chen, Y.-F. Bifunctional Polymer Nanocomposites as Hole-Transport Layers for Efficient Light Harvesting: Application to Perovskite Solar Cells. ACS Appl. Mater. Interfaces 2015, 7, 27676-27684. [CrossRef] 
113. Kim, K.; Yoo, S.; Huh, J.-H.; Park, Q.-H.; Lee, S. Limitations and Opportunities for Optical Metafluids to Achieve an Unnatural Refractive Index. ACS Photonics 2017, 4, 2298-2311. [CrossRef]

114. Rau, U.; Paetzold, U.W.; Kirchartz, T. Thermodynamics of light management in photovoltaic devices. Phys. Rev. B 2014, 90, 035211. [CrossRef]

115. Yuan, Z.; Wu, Z.; Bai, S.; Xia, Z.; Xu, W.; Song, T.; Wu, H.; Xu, L.; Si, J.; Jin, Y.; et al. Hot-Electron Injection in a Sandwiched $\mathrm{TiO}_{\mathrm{x}}-\mathrm{Au}-\mathrm{TiO}_{\mathrm{x}} \mathrm{Structure}$ for High-Performance Planar Perovskite Solar Cells. Adv. Energy Mater. 2015, 5, 1500038. [CrossRef]

116. Lu, L.; Luo, Z.; Xu, T.; Yu, L. Cooperative Plasmonic Effect of Ag and Au Nanoparticles on Enhancing Performance of Polymer Solar Cells. Nano Lett. 2012, 13, 59-64. [CrossRef] [PubMed]

117. Wu, J.-L.; Chen, F.-C.; Hsiao, Y.-S.; Chien, F.-C.; Chen, P.; Kuo, C.-H.; Huang, M.H.; Hsu, C.-S. Surface Plasmonic Effects of Metallic Nanoparticles on the Performance of Polymer Bulk Heterojunction Solar Cells. ACS Nano 2011, 5, 959-967. [CrossRef]

118. Zhang, W.; Saliba, M.; Stranks, S.D.; Sun, Y.; Shi, X.; Wiesner, U.; Snaith, H. Enhancement of Perovskite-Based Solar Cells Employing Core-Shell Metal Nanoparticles. Nano Lett. 2013, 13, 4505-4510. [CrossRef]

119. Quiroz, C.O.R.; Levchuk, I.; Bronnbauer, C.; Salvador, M.; Forberich, K.; Heumüller, T.; Hou, Y.; Schweizer, P.; Spiecker, E.; Brabec, C.J. Pushing efficiency limits for semitransparent perovskite solar cells. J. Mater. Chem. A 2015, 3, 24071-24081. [CrossRef]

120. Wu, R.; Yang, B.; Zhang, C.; Huang, Y.; Cui, Y.; Liu, P.; Zhou, C.; Hao, Y.; Gao, Y.; Yang, J. Prominent Efficiency Enhancement in Perovskite Solar Cells Employing Silica-Coated Gold Nanorods. J. Phys. Chem. C 2016, 120, 6996-7004. [CrossRef]

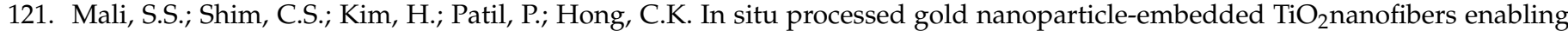
plasmonic perovskite solar cells to exceed 14\% conversion efficiency. Nanoscale 2016, 8, 2664-2677. [CrossRef]

122. Kim, G.M.; Tatsuma, T. Semitransparent Solar Cells with Ultrasmooth and Low-Scattering Perovskite Thin Films. J. Phys. Chem. C 2016, 120, 28933-28938. [CrossRef]

123. Kim, Y.H.; Sachse, C.; Machala, M.L.; May, C.; Müller-Meskamp, L.; Leo, K. Highly Conductive PEDOT:PSS Electrode with Optimized Solvent and Thermal Post-Treatment for ITO-Free Organic Solar Cells. Adv. Funct. Mater. 2011, 21, $1076-1081$. [CrossRef]

124. Gaynor, W.; Lee, J.-Y.; Peumans, P. Fully Solution-Processed Inverted Polymer Solar Cells with Laminated Nanowire Electrodes. ACS Nano 2009, 4, 30-34. [CrossRef]

125. Fortunato, E.; Ginley, D.; Hosono, H.; Paine, D.C. Transparent Conducting Oxides for Photovoltaics. MRS Bull. 2007, 32, $242-247$. [CrossRef]

126. Hu, L.; Kim, H.S.; Lee, J.-Y.; Peumans, P.; Cui, Y. Scalable Coating and Properties of Transparent, Flexible, Silver Nanowire Electrodes. ACS Nano 2010, 4, 2955-2963. [CrossRef]

127. Lee, K.-T.; Park, D.H.; Baac, H.W.; Han, S. Graphene- and Carbon-Nanotube-Based Transparent Electrodes for Semitransparent Solar Cells. Materials 2018, 11, 1503. [CrossRef]

128. Liu, Y.; Renna, L.; Bag, M.; Page, Z.; Kim, P.; Choi, J.; Emrick, T.; Venkataraman, D.; Russell, T.P. High Efficiency Tandem Thin-Perovskite/Polymer Solar Cells with a Graded Recombination Layer. ACS Appl. Mater. Interfaces 2016, 8, 7070-7076. [CrossRef]

129. Fu, F.; Feurer, T.; Jäger, T.; Avancini, E.; Bissig, B.; Yoon, S.; Buecheler, S.; Tiwari, A.N. Low-temperature-processed efficient semi-transparent planar perovskite solar cells for bifacial and tandem applications. Nat. Commun. 2015, 6, 8932. [CrossRef] [PubMed]

130. Bailie, C.D.; Christoforo, M.G.; Mailoa, J.P.; Bowring, A.R.; Unger, E.; Nguyen, W.H.; Burschka, J.; Pellet, N.; Lee, J.Z.; Grätzel, M.; et al. Semi-transparent perovskite solar cells for tandems with silicon and CIGS. Energy Environ. Sci. 2014, 8, 956-963. [CrossRef]

131. Kim, G.M.; Tatsuma, T. Semi-transparent Perovskite Solar Cells Developed by Considering Human Luminosity Function. Sci. Rep. 2017, 7, 10699. [CrossRef]

132. Ali, A.; Kang, J.H.; Seo, J.H.; Walker, B. Effect of Plasmonic Ag Nanoparticles on the Performance of Inverted Perovskite Solar Cells. Adv. Eng. Mater. 2019, 22, 1900976. [CrossRef]

133. Chen, L.-C.; Tien, C.-H.; Lee, K.-L.; Kao, Y.-T. Efficiency Improvement of MAPbI3 Perovskite Solar Cells Based on a CsPbBr 3 Quantum Dot/Au Nanoparticle Composite Plasmonic Light-Harvesting Layer. Energies 2020, 13, 1471. [CrossRef]

134. Kim, G.M.; Tatsuma, T. Photocurrent Enhancement of Perovskite Solar Cells at the Absorption Edge by Electrode-Coupled Plasmons of Silver Nanocubes. J. Phys. Chem. C 2017, 121, 11693-11699. [CrossRef]

135. Mohsen, A.A.; Zahran, M.; Habib, S.E.D.; Allam, N.K. Refractory plasmonics enabling 20\% efficient lead-free perovskite solar cells. Sci. Rep. 2020, 10, 6732. [CrossRef]

136. Saliba, M.; Zhang, W.; Burlakov, V.M.; Stranks, S.D.; Sun, Y.; Ball, J.M.; Johnston, M.; Goriely, A.; Wiesner, U.; Snaith, H.J. Plasmonic-Induced Photon Recycling in Metal Halide Perovskite Solar Cells. Adv. Funct. Mater. 2015, 25, 5038-5046. [CrossRef]

137. Lu, Z.; Pan, X.; Ma, Y.; Li, Y.; Zheng, L.; Zhang, D.; Xu, Q.; Chen, Z.; Wang, S.; Qu, B.; et al. Plasmonic-enhanced perovskite solar cells using alloy popcorn nanoparticles. RSC Adv. 2015, 5, 11175-11179. [CrossRef]

138. Liu, S.; Liang, L.; Meng, L.; Tian, X.; Zhang, Z.; Yu, Y.; Lan, Z.; Wu, J.; Zhang, J.; Gao, P. Synergy of Plasmonic Silver Nanorod and Water for Enhanced Planar Perovskite Photovoltaic Devices. Sol. RRL 2019, 4, 1900231. [CrossRef]

139. Fan, R.; Wang, L.; Chen, Y.; Zheng, G.; Li, L.; Li, Z.; Zhou, H. Tailored $A u @ T i O_{2}$ nanostructures for the plasmonic effect in planar perovskite solar cells. J. Mater. Chem. A 2017, 5, 12034-12042. [CrossRef]

140. Ghosh, J.; Giri, P.K. Effect of plasmonic metal nanoparticles on the performance of air processed inverted perovskite solar cells. In AIP Conference Proceedings; AIP Publishing LLC: Melville, NY, USA, 2019; Volume 2082, p. 050004. [CrossRef] 
141. Hu, Z.; García-Martín, J.M.; Li, Y.; Billot, L.; Sun, B.; Fresno, F.; Garcia-Martin, A.; González, M.U.; Aigouy, L.; Chen, Z. TiO 2 Nanocolumn Arrays for More Efficient and Stable Perovskite Solar Cells. ACS Appl. Mater. Interfaces 2020, 12, 5979-5989. [CrossRef]

142. Luo, Q.; Zhang, C.; Deng, X.; Zhu, H.; Li, Z.; Wang, Z.; Chen, X.; Huang, S. Plasmonic Effects of Metallic Nanoparticles on Enhancing Performance of Perovskite Solar Cells. ACS Appl. Mater. Interfaces 2017, 9, 34821-34832. [CrossRef] [PubMed]

143. Ginting, R.T.; Kaur, S.; Lim, D.-K.; Kim, J.-M.; Lee, J.H.; Lee, S.H.; Kang, J.-W. Plasmonic Effect of Gold Nanostars in Highly Efficient Organic and Perovskite Solar Cells. ACS Appl. Mater. Interfaces 2017, 9, 36111-36118. [CrossRef]

144. Irandoost, R.; Soleimani-Amiri, S. Design and analysis of high efficiency perovskite solar cell with ZnO nanorods and plasmonic nanoparticles. Optik 2019, 202, 163598. [CrossRef]

145. Kesavan, A.V.; Rao, A.D.; Ramamurthy, P.C.; Kesavan, A.V.; Rao, A.D.; Ramamurthy, P.C. Tailoring optoelectronic properties of $\mathrm{CH}_{3} \mathrm{NH}_{3} \mathrm{PbI}_{3}$ perovskite photovoltaics using al nanoparticle modified PC61BM layer. Sol. Energy 2021, 201, 621-627. [CrossRef] 